\title{
heartless encodes a fibroblast growth factor receptor (DFR1/DFGF-R2) involved in the directional migration of early mesodermal cells in the Drosophila embryo
}

\author{
Stephen Gisselbrecht, ${ }^{1}$ James B. Skeath, ${ }^{2}$ Chris Q. Doe, ${ }^{2}$ and Alan M. Michelson ${ }^{1,3}$ \\ ${ }^{1}$ Division of Genetics, Department of Medicine, Brigham and Women's Hospital, Harvard Medical School and Howard \\ Hughes Medical Institute, Boston, Massachusetts 02115 USA; ${ }^{2}$ Department of Cell and Structural Biology and Howard \\ Hughes Medical Institute, University of Illinois, Urbana, Illinois 61801 USA
}

\begin{abstract}
After invagination of the mesodermal primordium in the gastrulating Drosophila embyro, the internalized cells migrate in a dorsolateral direction along the overlying ectoderm. This movement generates a stereotyped arrangement of mesodermal cells that is essential for their correct patterning by later position-specific inductive signals. We now report that proper mesodermal cell migration is dependent on the function of a fibroblast growth factor (FGF) receptor encoded by heartless (htl). In htl mutant embryos, the mesoderm forms normally but fails to undergo its usual dorsolateral migration. As a result, cardiac, visceral, and dorsal somatic muscle fates are not induced by Decapentaplegic (Dpp), a transforming growth factor $\beta$ family member that is derived from the dorsal ectoderm. Visceral mesoderm can nevertheless be induced by Dpp in the absence of htl function. Ras1 is an important downstream effector of Htl signaling because an activated form of Ras1 partially rescues the $h t l$ mutant phenotype. The evolutionary conservation of $h t l$ function is suggested by the strikingly similar mesodermal migration and patterning phenotypes associated with FGF receptor mutations in species as diverse as nematode and mouse. These studies establish that Htl signaling provides a vital connection between initial formation of the embryonic mesoderm in Drosophila and subsequent cell-fate specification within this germ layer.
\end{abstract}

[Key Words: Receptor tyrosine kinase; cell migration; myogenesis; heart development; signaling; mesoderm]

Received June 10, 1996; revised version accepted October 14, 1996.

The mesoderm in Drosophila originates from the ventral-most cells of the blastoderm embryo. This germ layer is established by the function of an intricate hierarchy of maternal gene products whose interactions culminate in the graded nuclear expression of the transcription factor encoded by dorsal (dl) along the dorsoventral axis of the embryo (Morisato and Anderson 1995). High nuclear concentrations of $\mathrm{Dl}$ activate the transcription of two zygotic genes, twist (twi) and snail (sna), in cells of the mesodermal primordium (Jiang et al. 1991; Pan et al. 1991; Thisse et al. 1991; Ip et al. 1992). The early activities of these latter genes are essential for the specification of general mesodermal cell fate (Simpson 1983), whereas additional factors both intrinsic and extrinsic to this germ layer influence the subsequent differentiation of particular cells (Beer et al. 1987; Greig and Akam 1993; Michelson 1994; Staehling-Hampton et al. 1994;

${ }^{3}$ Corresponding author.
Baker and Schubiger 1995; Baylies et al. 1995; Frasch 1995; Wu et al. 1995; Baylies and Bate 1996; Ranganayakulu et al. 1996).

Twi/Sna-expressing mesodermal cells invaginate through the ventral furrow at gastrulation, an event that is accompanied by characteristic changes in cellular morphology that drive these cell movements (Leptin and Grunewald 1990; Kam et al. 1991; Sweeton et al. 1991; Leptin et al. 1992). Although it initially forms an epithelial tube, the mesoderm subsequently loses this appearance as the invaginated cells flatten, disperse, and undergo a series of mitotic divisions (Leptin and Grunewald 1990; Bate 1993|. Simultaneously, the mesodermal cells begin to migrate in a dorsolateral direction beneath the overlying ectoderm until they attain a uniform monolayer that reaches as far as the dorsal margin of the epidermis. After an additional cell division, the mesoderm is subdivided into an inner or visceral layer and an outer or somatic layer (Bate 1993; Dunin Borkowski et al. 1995). 
The visceral mesoderm is demarcated by the expression domains of two homeo domain-encoding genes, tinman (tin) and bagpipe (bap), the activities of which are required for the formation of this dorsal derivative $\mid \mathrm{Az}$ piazu and Frasch 1993; Bodmer 1993). tin function is also essential for differentiation of the heart, another derivative of the dorsal mesoderm. Furthermore, the dorsal subdivision of the mesoderm is dependent on proximity of this germ layer to cells of the dorsal ectoderm that supply a diffusible, inductive signal in the form of a transforming growth factor $\beta$ (TGF $\beta$ ) family member encoded by the decapentaplegic $(d p p)$ gene (StaehlingHampton et al. 1994; Frasch 1995). Thus, dorsolateral migration of mesodermal cells is absolutely essential for the acquisition of particular cell fates through induction by the adjacent ectoderm. Modulation of the level of Twi expression along the anteroposterior axis also is critical to the partitioning of the embryonic mesoderm into its various components (Dunin Borkowski et al. 1995; Baylies and Bate 1996).

Although the early steps in mesoderm formation are well delineated, the genetic and molecular control of later morphogenetic events within this germ layer remain poorly understood. We now demonstrate that the activity of a fibroblast growth factor (FGF) receptor is essential for the proper directional migration of mesodermal cells following their invagination at the onset of gastrulation. In the absence of this receptor tyrosine kinase (RTK) signaling pathway, the invaginated mesodermal cells initially do not dissociate from each other nor do they spread correctly beneath the ectoderm. Subsequent patterning of this germ layer is grossly disrupted as specific mesodermal cells fail to acquire proper positional cues for their later commitment and differentiation. This is particularly evident in the dorsal region of the mesoderm where the induction of cardiac, somatic, and visceral muscle fates is dependent on a growth factor signal produced by the dorsal ectoderm (StaehlingHampton et al. 1994; Frasch 1995). As a consequence, one of the most prominent features of FGF receptor-deficient embryos is the absence of the heart or dorsal vessel, a phenotype which has led us to name this gene heartless ( $h t l)$. Next to twi and sna, $h t l$ has the earliest characterized function of a zygotically expressed mesoderm-specific gene.

\section{Results}

\section{Isolation of mesodermal FGF receptor mutants}

The pair-rule gene, even-skipped (eve), is expressed in a small number of dorsal mesodermal cells following its segmentation function in the early Drosophila embryo (Frasch et al. 1987). As development proceeds, Eve persists in two mesodermal derivatives, a subset of pericardial cells, and a single dorsal somatic muscle in each hemisegment (Fig. 1A). We have found that the specification of the Eve-positive muscle but not the pericardial cells is dependent on the activity of the Drosophila epidermal growth factor (EGF) receptor (E. Buff and A.M.

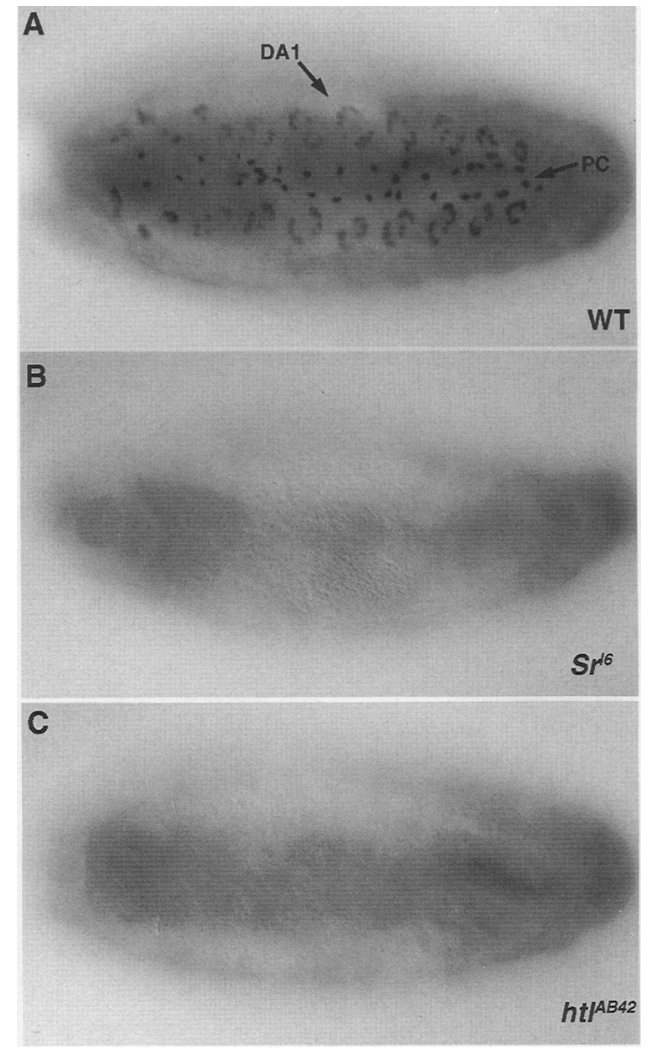

Figure 1. Mesodermal Eve expression in homozygous $\mathrm{Sr}^{16}$ and $h t t^{A B 42}$ embryos. Dorsal views of stage 16 wild-type (WT;A), $S r^{16}(B)$, and $h t l^{A B 42}(C)$ embryos stained with an antibody directed against Eve. Anterior is to the left. Eve is normally expressed in a pair of pericardial cells (PC) and a single dorsal somatic muscle (dorsal acute 1 or DA1; muscle nomenclature after Bate 1993) in each hemisegment. In embryos homozygous for the $\mathrm{Sr}^{16}$ deficiency in which the DFR1/htl gene is deleted (Shishido et al. 1993), none of the Eve-expressing mesodermal cells is present $(B)$. A similar phenotype is seen in a null allele of $h t l|C|$.

Michelson, unpubl.). In contrast, loss of maternal and zygotic function of Rasl, an important downstream effector of RTK signal transduction pathways (Lowy and Willumsen 1993; van der Geer and Hunter 1994|, leads to loss of both Eve-expressing mesodermal cell types (A.M. Michelson, unpubl.). The latter finding suggested that an additional RTK might be involved in the formation of at least these dorsal mesodermal derivatives. One candidate for this RTK is a mesoderm-specific FGF receptor, designated DFR1 (Shishido et al. 1993) or DFGFR2 (cited in Reichman-Fried et al. 1994). This Drosophila gene was cloned on the basis of its homology to vertebrate FGF receptors, and was mapped to the right arm of the third chromosome in a region that is uncovered by the $\mathrm{Sr}^{16}$ deficiency (DeLaPompa et al. 1989; Bellen et al. 1992; Shishido et al. 1993). Consistent with the possible requirement of DFR1/DFGF-R2 for the development of Eve-positive pericardial and somatic muscle cells, $\mathrm{Sr}^{16}$ 
homozygous embryos entirely lack Eve expression in the dorsal mesoderm (Fig. 1B).

Because several genes are known to fall within the $\mathrm{Sr}^{16}$ deficiency (DeLaPompa et al. 1989; Bellen et al. 1992; Shishido et al. 1993; Volk and VijayRaghavan 1994), mutations specific to the DFR1/DFGF-R2 gene are required to confirm a role for this RTK in mesodermal pattern formation. We have identified several such alleles in a screen of third chromosome embryonic lethal mutations induced by the chemical mutagen ethylmethanesulfonate (EMS). A collection of $\sim 4000$ independently generated lethal lines was screened for aberrant Eve expression in both the mesoderm and the central nervous system (J.B. Skeath and C.Q. Doe, unpubl.). From this screen, 49 lines were identified in which the mesodermal Eve pattern was altered but the CNS Eve pattern was not appreciably affected. Of these, seven lines failed to complement $\mathrm{Sr}^{16}$. Furthermore, these seven mutants were found to constitute a single complementation group. As was the case with $\mathrm{Sr}^{16}$, neither pericardial nor somatic muscle cells expressing Eve are found in an embryo homozygous for a representative allele (Fig. 1C). Definitive evidence that this phenotype is attributable to loss of mesodermal FGF receptor function was obtained by sequence analysis of the DFR1/DFGF-R2 genes cloned from six members of this complementation group (see below).

Cardiac, somatic, and visceral mesodermal derivatives are all dependent on FGF receptor function

Eve is expressed in only a small subset of embryonic mesodermal cells. To further characterize the phenotypes associated with loss of mesodermal FGF receptor function, we examined the development of the heart, somatic, and visceral muscles in one mutant line, designated $A B 42$. The phenotypes observed in homozygous $A B 42$ embryos are equivalent to those of $A B 42 / S r^{16}$, suggesting that $A B 42$ is a null allele. As described below, molecular characterization of the DFR1/DFGF-R2 gene in $A B 42$ confirms that it represents complete loss of function of mesodermal FGF receptor activity.

A monoclonal antibody that reacts with an antigen expressed on all pericardial cells of the normal embryonic heart ( $T$. Volk, pers. comm.) detects only a few such cells in the $A B 42$ mutant (Fig. 2A, F). When comparing multiple mutant embryos of the same genotype, the locations of these residual pericardial cells appear to be randomly distributed (data not shown). Similarly, there is a marked reduction in the number of cardial cells as revealed by expression of tin transcripts (Fig. 2 B,G) as well as myosin heavy chain (Fig. 2C,H) and D-MEF2 (Fig. $7 \mathrm{~B}, \mathrm{C})$ proteins. Based on this striking defect in cardiac development, we have named this gene heartless (htl). However, the developmental defects in htl mutant embryos are not restricted to this mesodermal derivative. Most of the dorsal somatic muscles are entirely missing (Fig. $2 \mathrm{C}, \mathrm{H}$ ), and gaps are seen in the lateral and ventral muscle groups as well (Fig. 2D,I). Again, there is considerable variability among embryos in the precise muscles

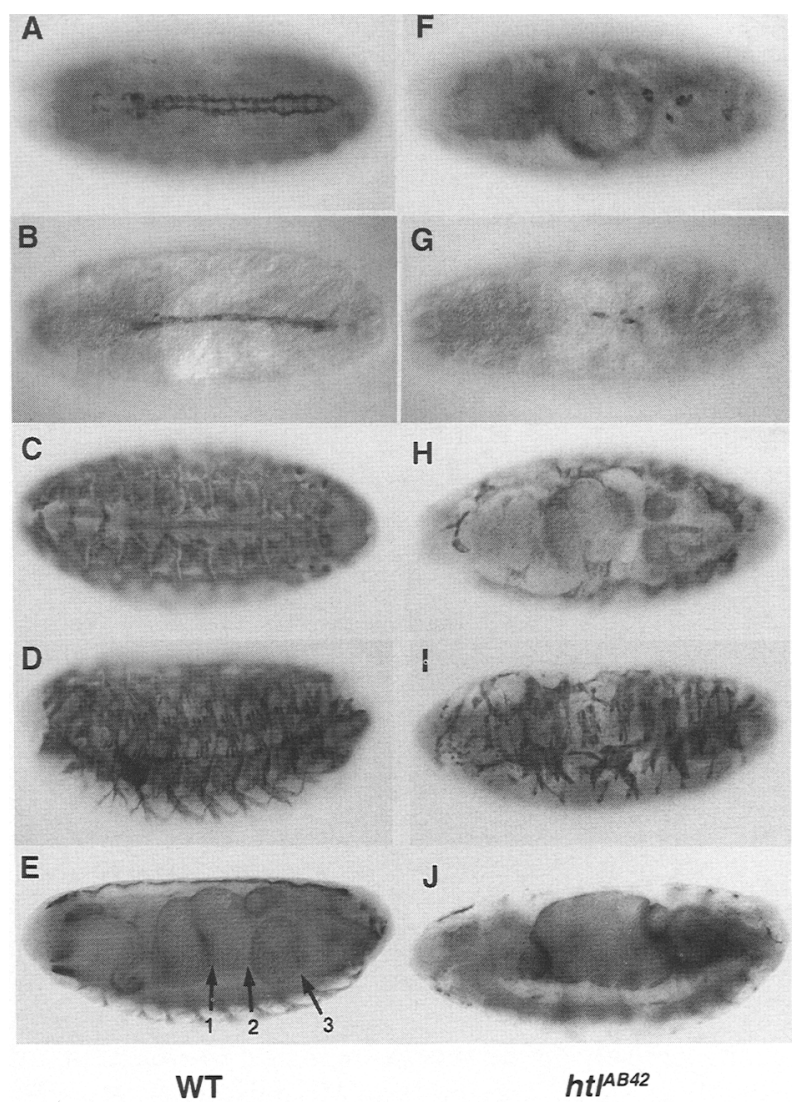

Figure 2. Cardiac, visceral, and somatic muscle defects in $h t l$ mutant embryos. Stage 16 wild-type (WT; $A-E)$ and $h t 1^{A B 42} \mathrm{mu}-$ $\tan (F-I)$ embryos were examined for expression of a number of markers of mature mesodermal derivatives. Dorsal views are shown in $A-C$ and $F-H$; anterior is to the left. Lateral views are shown in $D, E, I$ and $J$; anterior is to the left and dorsal is up. $(A$, $F)$ Pericardial cells of the embryonic heart were visualized using a specific monoclonal antibody ( $T$. Volk, pers. comm.). Only a few scattered pericardial cells remain in the dorsal mesoderm of the $h t l$ mutant. Independent mutant embyros show varying numbers of residual pericardial cells in different locations along the anteroposterior axis (data not shown). $(B, G)$ Cardiac cells were revealed by in situ hybridization with a tin probe. Only a few randomly distributed tin-expressing cells are seen in the mutant, although these are confined to the dorsal midline as in wild type. $(C, H)$ Myosin heavy chain expression is greatly reduced in the dorsal mesoderm of the htl mutant embryo, indicating that the majority of dorsal somatic muscles and cardial cells are missing. $(D, I)$ Numerous somatic muscles are also absent from the dorsal and lateral groups in the htl mutant, as indicated by staining for myosin heavy chain expression. $(E, /)$ Myosin heavy chain expression in the visceral mesoderm. The normal midgut develops three constrictions at this stage larrows in $E$ ). These constrictions fail to form in the absence of $h t l$ function, and the midgut retains a bloated appearance.

that are missing in the latter locations. Of further note, a few unfused myoblasts expressing myosin heavy chain can be seen in htl mutant embryos, and the myofibers that do develop in these embryos form a relatively normal residual pattern (Fig. 2I). 
In addition, the visceral musculature fails to undergo its normal morphogenesis in the absence of $h t l$ function. Whereas the midgut acquires three constrictions in normal embryos (Fig. 2E), this fails to occur in $h t l$ mutants (Fig. 2J). This gut phenotype resembles that associated with mutations in bap (Azpiazu and Frasch 1993) and D-mef2 (Bour et al. 1995; Lilly et al. 1995; Ranganayakulu et al. 1995). Other mesodermal tissues, including the fat body and hemocytes, appear largely normal in the absence of $h t l$ function, as do ectodermal derivatives such as the cuticle and central nervous system /data not shown). The latter finding is of particular significance because the Htl FGF receptor is expressed in a small number of cells in the developing nervous system (Shishido et al. 1993).

\section{Early progenitors of each of the affected mesodermal derivatives fail to form in htl mutant embryos}

Given the defects observed for various differentiated mesodermal derivatives, we used a series of markers for the corresponding progenitors to identify when in development the FGF receptor is required. Eve-expressing precursors of both the pericardial cells and dorsal somatic muscle were absent from stage 13 mutant embryos (Fig. $3 \mathrm{~A}, \mathrm{E})$. These cells also were missing at stage 10 when they first appear in normal embryos (data not shown). Specific muscle precursors expressing nautilus (nau), the Drosophila MyoD homolog (Michelson et al. 1990; Paterson et al. 1991), and Kruppel (Kr; Gaul et al. 1987) were also missing from $h t l$ embyros (Fig. 3B,C,F,G). In both cases, there was considerable variation in the pattern defects among different segments of the same or different embryos, and the dorsal precursors were more strongly reduced in number than those in the lateral and ventral groups.

The variability of the somatic muscle defects associated with $h t t^{A B 42}$ was quantitated for $\mathrm{Kr}$-positive dorsal, lateral, and ventral abdominal muscle precursors (see Materials and Methods). As illustrated in Figure 3C, $\mathrm{Kr}$ normally is expressed in two dorsal muscles (DAl and DO1), several lateral muscles (LL1 and two LT muscles), and a ventral acute muscle (VA2; additional ventral muscles expressing $\mathrm{Kr}$ are out of the plane of focus in Fig. $3 \mathrm{C}$. Whereas an average of only $10.8 \pm 7.7 \%$ of DAl or DO1 muscle precursors was present per embryo, $56.9 \pm 13.7 \%$ of abdominal hemisegments contained LL1 and $98.0 \pm 3.7 \%$ contained VA2 $(\mathrm{n}=28$ embryos or 392 abdominal hemisegments). Thus, there is both an increasing severity and variability in muscle loss from ventral to dorsal positions of $h t l$ mutant embryos.

The findings with somatic muscle precursor markers parallel the defects in the mature myofiber pattern, as described above (Fig. $2 \mathrm{H}, \mathrm{I}$ ). In addition to the loss of specific precursors revealed by the Eve, Nau, and $\mathrm{Kr}$ patterns, there was a generalized reduction in muscle precursor number as indicated by D-MEF2 expression in the somatic mesoderm, with the most marked effect again evident in the dorsal region (Fig. 3D,H). The latter marker also demonstrated that cardial cell precursors
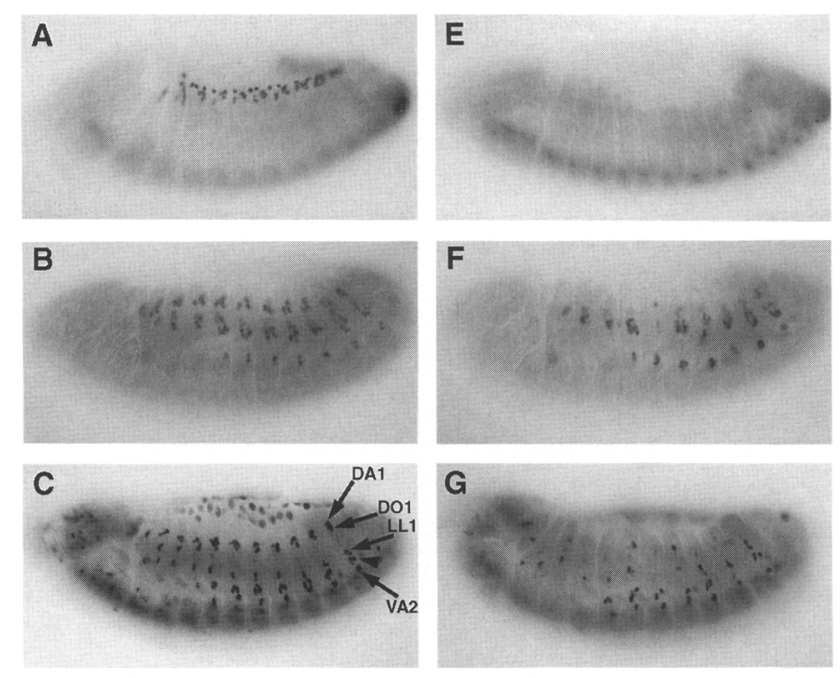

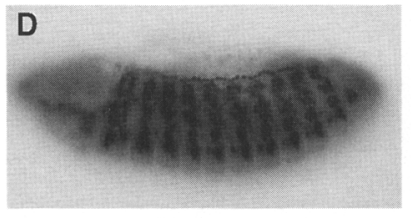

WT

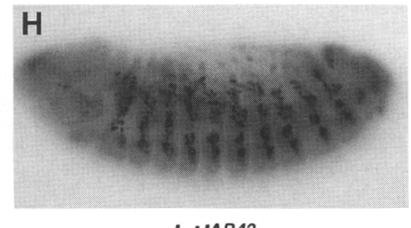

$h t^{A B 42}$
Figure 3. Loss of htl function affects the development of somatic muscle precursors. Lateral views of wild-type $(\mathrm{WT} ; A-D)$ and $h t l^{A B 42}(E-H)$ stage 13 embryos stained with $\alpha$-Eve $(A, E)$, $\alpha$-Nau $(B, F), \alpha-\operatorname{Kr}(C, G)$, and $\alpha$-DMEF2 $(D, H)$. Anterior is to the left and dorsal is up. In each case, multiple muscle precursors are missing from the $h t l$ mutant. This reduction is more severe in dorsal than in lateral and ventral regions. Note that there is considerable variability among segments in the specific muscle precursors that are absent, and additional variability is seen in comparing different mutant embryos (see text for quantitative assessment of this phenotype). Arrows in $C$ point to $\mathrm{Kr}$-expressing muscle precursors that were quantitated in $h t l^{A B 42}$ mutant embryos, and include dorsal acute muscle 1 (DA1), dorsal oblique muscle 1 (DO1), lateral longitudinal muscle 1 (LL1), and ventral acute muscle 2 (VA2; muscle nomenclature is after Bate 1993). Arrowhead in $C$ indicates two additional $\mathrm{Kr}$-expressing lateral transverse muscles. Other ventral $\mathrm{Kr}$-positive muscle precursors are located at more internal positions within the mesoderm and are out of the plane of focus in $C$.

were largely absent at stage 13 (Fig. 3D,H), and even at earlier developmental times (data not shown).

tin initially is expressed throughout the mesoderm but then becomes restricted to the dorsal region in wild-type embryos (Azpiazu and Frasch 1993; Bodmer 1993) Fig. 4A). As early as stage 10, this dorsal domain of tin expression is significantly reduced in $h t l$ mutants (Fig. 4E). Slightly later, the tin pattern normally is subdivided into two parts, an outer cardiac and an inner visceral component (Fig. 4B). There is an overall reduction of both regions in $h t l$ mutant embryos, but the cardiac domain is much more severely affected than the visceral (Fig. 4F). As predicted by this abnormal expression of tin, the numbers of bap-and Fasciclin III-expressing cells in the visceral mesoderm are severely diminished (Fig. 4C-H). 

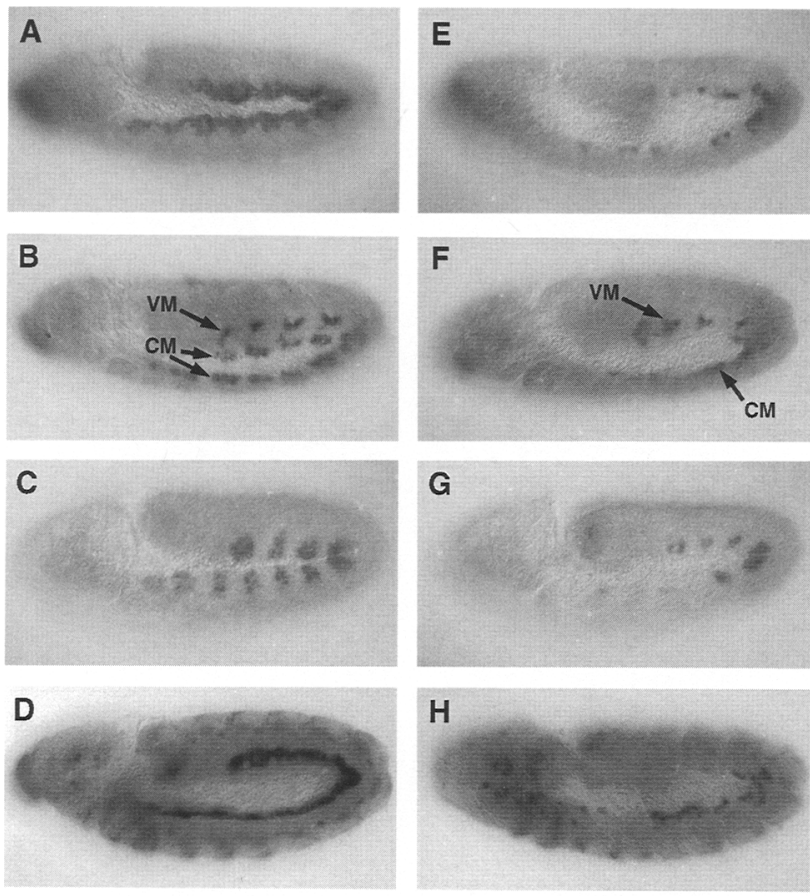

WT
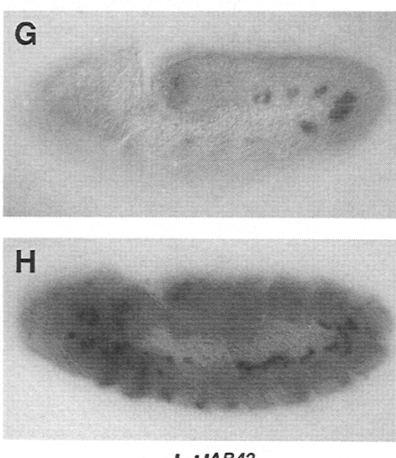

$h t /^{A B 42}$

Figure 4. $h t l$ is required for proper specification of the cardiac and visceral mesoderm. Lateral views of wild-type $(\mathrm{WT} ; A-D)$ and $h t t^{A B 42}(E-H)$ embryos are shown with anterior to the left in each case. $\{A, E)$ tin transcripts normally are expressed at stage 10 in a broad but dorsally restricted domain that is markedly reduced in the absence of $h t l$ function. $(B, F)$ By stage 11 , dorsal tin expression resolves into visceral (VM) and cardiac (CM) domains. Both the VM and CM are significantly diminished in the htl mutant, but note that the CM is more severely affected. $(C, G)$ bap transcripts are expressed in the visceral mesoderm of a stage 10 wild-type embryo in a series of segmentally repeated patches along the anteroposterior axis. This pattern is greatly reduced in the htl mutant, with some segments showing little or no bap expression in the visceral mesoderm while others contain small clusters of bap-positive cells. $(D, H)$ Fasciclin III protein is found in a continuous ribbon of visceral mesodermal cells in a stage 11 wild-type embryo. Significantly fewer Fasciclin III-expressing cells are found in the visceral mesoderm of an age-matched htl mutant embryo.

Thus, in all cases where mature mesodermal tissues are dependent on $h t l$ function, the defect /and its relative severity) can be traced to an early developmental stage.

\section{htl function is essential for the normal dorsolateral migration of mesodermal cells}

Because the dorsally restricted domain of tin expression was abnormal in $h t l$ embryos, we examined the earlier, panmesodermal tin pattern. As shown in Figure 5A and $\mathrm{D}$, the complement of tin-expressing cells in stage $9 \mathrm{htl}$ mutant embryos does not encompass its normal dorsal limit. An identical phenotype is seen with both D-MEF2 and Twi expression at the same stage of development (Fig. 5B,C,E,F). With each of these three markers, the dorsolateral edge of the mesoderm in $h t l$ embryos has an irregular margin that falls significantly short of the dorsal ectoderm when compared with age-matched wildtype controls.

After invagination of the mesoderm at gastrulation, further differentiation involves loss of the epithelial character of the internalized cells, several rounds of mitosis, and migration along the overlying ectoderm. Together these processes generate an inner layer of mesoderm that spans the entire dorsoventral axis of the embryo (Leptin and Grunewald 1990; Bate 1993). The abnormal appearance of the mesoderm in stage $9 \mathrm{htl} \mathrm{mu-}$ tant embryos could be attributable to a defect in any one or a combination of these processes. That is, an inadequate number of cells could invaginate, the cells could fail to proliferate, or they could remain aggregated and fail to migrate toward the dorsal ectoderm. To distinguish among these possibilities, transverse sections of Twi-stained wild-type and mutant embryos were compared at various stages of development. This analysis revealed that there is no reduction in the initial number of invaginated Twi-positive mesodermal cells in htl embryos (Fig. 6A,B). Furthermore, the population of mutant mesodermal cells expands appropriately by cell division (Fig. 6C-H). However, in mutant embryos, the mesodermal cell mass initially remains aggregated and does not undergo the full extent of dorsal migration characteristic
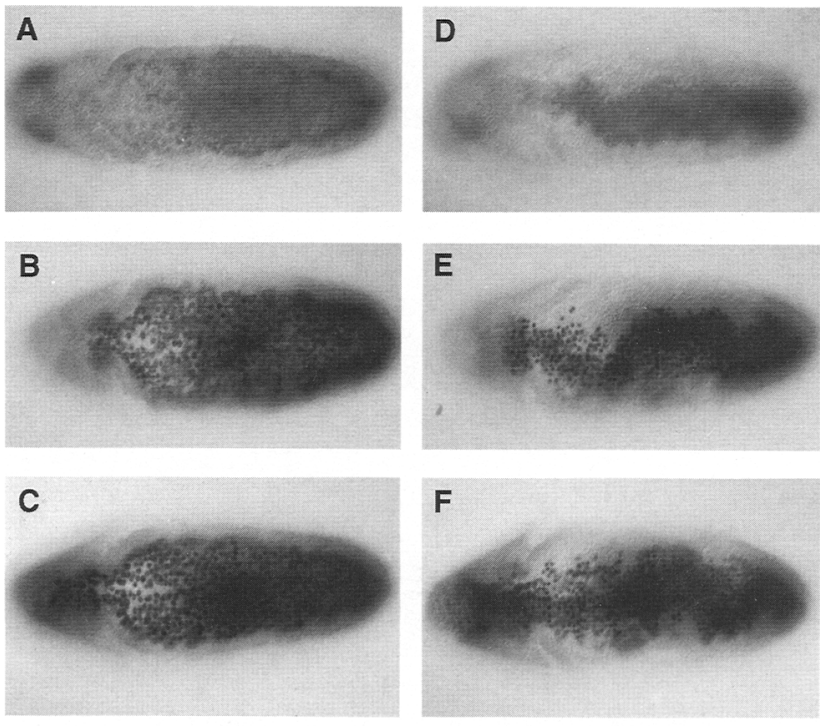

WT

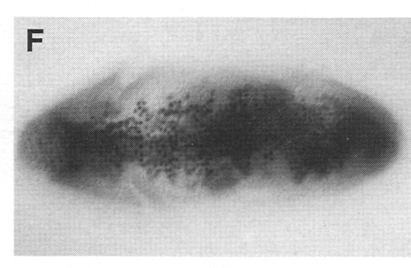

$h t / /^{A B 42}$

Figure 5. Early mesodermal phenotype associated with loss of $h t l$ function. Ventral views of stage 9 wild-type $(\mathrm{WT} ; A-C)$ and $h t t^{A B 42}(D-F)$ embryos are shown stained for expression of tin $(A, D)$, DMEF2 $(B, E)$, and Twist $(C, F)$. By this stage, mesodermal cells uniformly expressing all three markers have migrated to form a monolayer that spans the full extent of the dorsoventral axis in wild-type embryos (also see Fig. 6E). In contrast, the mesoderm does not reach the dorsal ectoderm in the absence of $h t l$ function, and the dorsolateral edge of the mutant mesoderm forms an irregular margin along the anteroposterior axis. 
Figure 6. $h t l$ is required for the proper dorsolateral migration of the embryonic mesoderm. Transverse sections $(5 \mu \mathrm{m}$-thick) of wild type (WT; $A, C, E, G)$ and $h t I^{A B 42}(B, D, F, H-K)$ Twist-stained embryos are shown at four different developmental stages. $(A, B)$ Stage 8: The mesodermal primordium has invaginated and begun to disaggregate and spread laterally along the inner surface of the ectoderm in the wild-type embryo. In contrast, in the htl mutant, the mesodermal cells remain clustered close to the ventral midline /ventral is toward the bottom of the panels; these sections are anterior to the extending germ band so that amnioserosa is visible at the top|. Note that a normal number of mesodermal cells is present in the mutant. $(C, D)$ Stage 9: The number of mesodermal cells increases in both wild-type and mutant embryos, but only in the former do they continue to migrate in a dorsolateral direction on both sides of the extended germ band. $(E, F)$ Early stage 10: Whereas the wild-type mesoderm has formed a monolayer that spans the complete dorsoventral axis of the embryo, the $h t l$ mutant mesodermal cells remain in a multilayered collection that has undergone incomplete lateral spreading. Note that mutant cells even appear deep within the central yolk cavity. $(G, H-K)$ Mid- to late stage 10 : Further cell division has caused an expansion of the mesoderm in both wild-type and mutant embryos. The sections in $H-K$ are from the same $h t t^{A B 42}$ embryo and are spaced $20 \mu \mathrm{m}$ apart, thus representing two adjacent segments on either side of the extended germ band. There is considerable variability in the shape of the mesodermal cell mass in these serial sections, as well as in the number of cells that are in proximity to the ectoderm at any given level along the dorsoventral axis. For example, on one side of the ventral midline in the lower part of panel $I$, there are no Twist-expressing nuclei near the lateral ectoderm, whereas on the other side several mesodermal cells extend to a midlateral position.

of its wild-type counterparts. By early stage 10 , the mutant mesoderm appears as a multilayered collection of cells on either side of the extended germ band instead of a monolayer beneath the ectoderm (Fig. 6E,F). Mesodermal cells are even found in the middle of the central yolk cavity, suggesting that they are capable of migrating but not in the proper direction (Fig. 6F). Further proliferation occurs in the mesoderm of later stage 10 wild-type and htl mutant embryos (Fig. 6G-K).

The randomness of the cell migration that occurs in the absence of $h t l$ function is more clearly revealed by the serial sections shown in Figure $6 \mathrm{H}-\mathrm{K}$. These 5$\mu \mathrm{m}$ thick sections from the same mutant embryo are spaced $20 \mu \mathrm{m}$ apart along the anteroposterior axis and reveal a striking variation in the arrangement of mesodermal cells beneath the ectoderm. This variability is not seen in comparable wild-type embryos /data not shown). Although there consistently is a complete absence of mesodermal cells in the most dorsal positions, there is also considerable variability in the number of these cells at more ventral and lateral levels. The non-
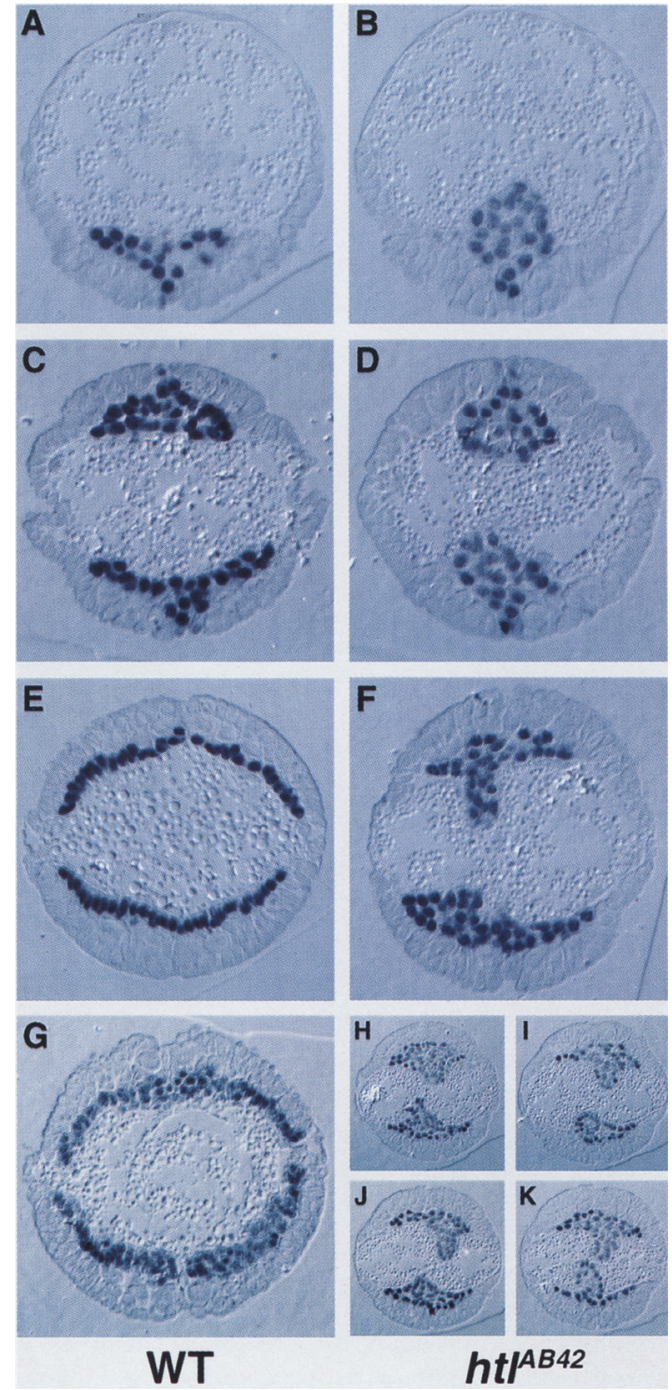

uniform appearance of the mutant mesoderm is particularly impressive when considering that these four sections span two adjacent segments on either side of the extended germ band. This early defect prefigures the graded phenotypic severity along the dorsoventral axis that has already been described for the mature mesodermal derivatives and their precursors. These findings indicate that $\mathrm{Htl}$ is essential for the normal dorsolateral migration of the embryonic mesoderm.

\section{An allelic series of htl mutations}

To obtain definitive evidence that $h t l$ encodes DFRl/ DFGF-R2, the previously described mesoderm-specific FGF receptor (Shishido et al. 1993), we identified molecular lesions in the DFR1/DFGF-R2 coding region for six of our seven $h t l$ alleles. The analysis was begun by PCR amplification of the DFR1/DFGF-R2 genomic region from wild-type and mutant strains. Because the DFR1/ DFGF-R2 coding sequence lacks introns /Shishido et al. 
1993), primers in the $5^{\prime}$ - and $3^{\prime}$-untranslated regions were used to amplify this entire sequence as a single $2.3-\mathrm{kb}$ fragment. This approach immediately revealed an internal deletion of $\sim 200 \mathrm{bp}$ that mapped to the $3^{\prime}$-end of the DFR1/DFGF-R2 coding sequence in one of the mutant lines, $h t l^{Z Z 81}$ (data not shown). Sequencing of this segment in $h t 1^{Z Z 81}$ precisely mapped the deletion breakpoints to nucleotides 1901-2087 (nucleotide numbers are in accord with Shishido et al. 1993). In addition, two novel nucleotides were inserted in the deleted region, thus introducing a frameshift and 11 novel amino acids followed by a premature stop codon (Fig. 7A). The net result is that the carboxyl terminus of the tyrosine kinase domain of the mesodermal FGF receptor is truncated in $h t l^{Z Z 81}$

The remaining six $h t l$ alleles yielded full-length coding regions by PCR amplification. To facilitate the rapid identification of additional molecular lesions in the FGF receptors encoded by these mutants, we scanned their coding regions using the single-strand conformation polymorphism (SSCP) technique (Orita et al, 1989). This approach localized sequence variations to single, $\sim 200$ bp segments for each allele (data not shown). These target regions were sequenced from at least two independent PCR reactions for five of the remaining $h t l$ mutant lines. The FGF receptor/htl gene from the parental isogenic red $e$ chromosome used in the original mutagenesis was sequenced in its entirety as a wild-type reference. The latter analysis revealed several differences from the previously reported DFR 1 sequence (Fig. 7A). All of these nucleotide variations were confirmed in an additional normal $h t l$ gene, this one isolated from another lethalbearing red $e$ chromosome that was obtained from the screen and which complemented the $S r^{16}$ deficiency as well as an actual $h t l$ allele (data not shown). The differences between our wild-type $h t l$ sequence and that published for DFR1 may represent strain-specific polymorphisms. However, these sequence variations have no bearing on our htl alleles because in each case the mutant FGF receptor differs from the parental version at a

\begin{abstract}
A
1 MTSGSVVVLF LLLTIWQPAV QVEGRRQMAN SQEMIKDHLG ARSQNKTPAI

51 TNNANQSSTS SADLDDGAAD DDDNKADLPV NVSSKPYWRN PKKMSFLQTR

101 PSGSLLTLNC HALGNPEPNI TWYRNGTVDW TRGYGSLKRN RWTLTMEDLV

151 PGDCGNYTCK VCNSLGCIRH DTQVIVSDRV NHKPILMTGP LNLTLVVNST

201 GSMHCKYLSD LTSKKAWIFV PCHGMTNCSN NRSIIAEDKD QLDFVNVRME

251 QEGWYTCVES NSLGQSNSTA YLRVVRSLHV LEAGVASGSL HSTSEVYIEV

301 FGGLIFIFMT TLFVFYAIRK MKHEKVLKQR IETVHQWTKK VIIFKPEGGG

351 DSSGSMDTMI MPVVRIQKQR TTVLQNGNEP APFNEYEFPL DSNWELLRSH

$401 \frac{\text { LVLGATLGEG AFGRVVMAEV NNAIVAVKMV KEGHTDDDIA SLVREMEVMK }}{\text { ह }}$

451 IIGRHINIIN LLGCCSONGP LYVIVEYAPH GNLKDFLYKN RPFGRDQDRD

501 SSQPPPSPPA HVITEKDLIK FAHOIARGMD YLASRRCIHR DLAARNVLVS

551 DDYVLKIADF GLARDIOSTD YYRKNTNGRL PIKWMAPESL OEKFYDSKSD

601 VWSYGILLWE IMTYGOOPYP TIMSAEELYT YLMSGORMEK PAKCSMNIYI

651 LMROCWHFNA DDRPPFTEIV EYMDKLLQTK EDYLDVDIAN LDTPPSTSDE

701 EEDETDNLQK WCNY
\end{abstract}
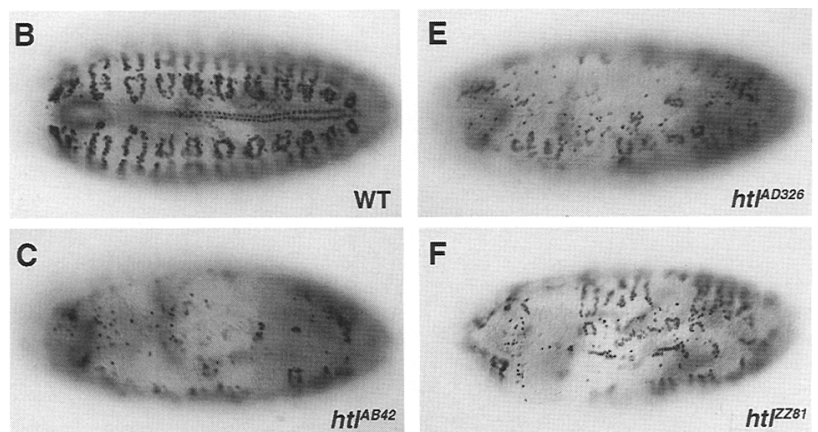

F

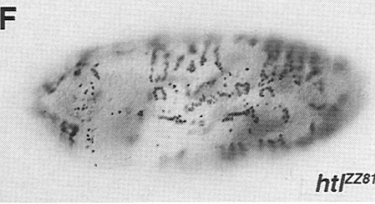

D

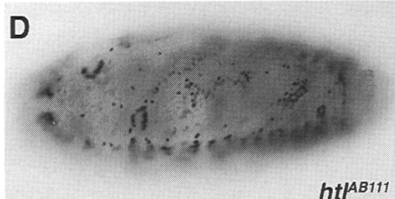

G

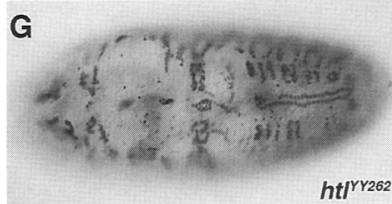

Figure 7. Molecular lesions and variable phenotypes of a series of $h t l$ alleles. (A) The amino acid sequence of the Htl/DFRI protein is shown in the one-letter code. The signal sequence is italicized, the transmembrane domain is boxed, and the kinase domain is underlined / the break in the line represents the kinase insertion). Where our results differ from the published sequence, the published amino acid is indicated in parentheses. Bold letters below the wild-type sequence indicate positions at which missense mutations were identified in $h t l$ alleles: $h t 1^{A B 111}$ has a glycine to glutamate change at position 408 in the canonical glycine-rich loop, and both $h t l^{Y Y 262}$ and $h t l^{A D 332}$ have a glutamate to lysine substitution at position 588 . Dots $(\cdot)$ below the sequence indicate residues that are changed to stop codons. In $h t l^{A B 42}$ a nonsense codon occurs at position 276 whereas in $h t I^{A D 326}$ there is a nonsense codon at position 524 . The asterisk indicates the last wild-type amino acid present in $h t 1^{Z Z 81}$; a 187-bp deletion (with insertion of two novel nucleotides/replaces the remainder of the protein with the sequence DRRSATFYGNRStop. $(B-G)$ D-MEF2 expression in wild-type (WT) and five $h t l$ alleles, as indicated by the label in each panel. A dorsal view of a stage 16 embryo is shown in each case. D-MEF2 is normally expressed in the cardial cells of the heart and in all of the somatic muscles. In $h t l^{A B 42}, h t l^{A B 111}$, and $h t I^{A D 326}$ there is an equally strong reduction in the number of D-MEF2-expressing mesodermal cells in the dorsal region. In contrast, a significant number of both dorsal muscles and cardial cells develop in $h t l^{Y Y 262}$. The phenotype of $h t l^{Z Z 81}$ is intermediate between that of the strong group and that of $h t l^{\text {YY262 }}$. 
single nucleotide that can be interpreted as having a deleterious effect on FGF receptor activity.

In $h t l^{A B 42}$, cytosine 935 is mutated to thymine, thus introducing a premature nonsense codon. Because this site lies just amino-terminal to the transmembrane domain of the FGF receptor (Fig. 7A), no functional receptor should be produced by this mutant gene, and the homozygous phenotype should be that of a null allele. As discussed previously, this allele behaves genetically as an amorph and, along with two other alleles, exhibits the strongest phenotype of our $h t l$ mutants (see below).

The FGF receptor gene in $h t l^{A B 111}$ contains a guanine to adenine transition at nucleotide 1332, that changes a glycine codon to glutamate (Fig. 7A). This corresponds to the first invariant glycine in the canonical glycine-rich loop of protein kinases (Bossemeyer 1994; Hanks and Hunter 1995). A bulky amino acid side chain such as that of glutamate in this position is predicted to interfere significantly with ATP binding, thus severely compromising RTK function (Bossemeyer 1994; Hanks and Hunter 1995; Mohammadi et al. 1996). The $h t t^{A D 326}$ mutation is a cytosine to thymine transition at nucleotide 1679 . This creates a nonsense codon just carboxy-terminal to the insert in the tyrosine kinase domain, thus deleting nearly 200 amino acids of the intracellular domain of the receptor (Fig. 7A). In addition to the potential adverse effect of this large deletion on folding of the kinase domain, catalytic function may be severely compromised because the deleted segment includes the critical aspartate residue that is thought to deprotonate the phosphate acceptor on the peptide substrate (Taylor et al. 1992; Hanks and Hunter 1995). Finally, two independent al-

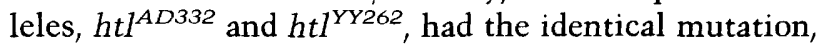
a guanine to adenine transition at position 1871 that changes a glutamate codon to lysine (Fig. 7A). Based on homology among different classes of protein kinases (Taylor et al. 1992; Hanks and Hunter 1995), and in particular to human FGFR1 for which the crystal structure has been determined (Mohammadi et al. 1996), the affected glutamate in Htl should normally form a stabilizing salt bridge with arginine 663 . This structure would be disrupted by the glutamate to lysine mutation in $h t 1^{A D 332}$ and $h t 1^{Y Y 262}$ and lead to at least a partial reduction in kinase activity (see below).

Given the established structures of the FGF receptors encoded by our $h t l$ alleles, we have attempted to make structure-function correlations by ordering the mutants into a series based on phenotypic severity. Because dorsal mesodermal derivatives are most sensitive to partial loss of $\mathrm{Htl}$ activity, we used the expression of D-MEF2 in the heart and dorsal somatic muscles of stage $16 \mathrm{em}$ bryos as an indicator of phenotypic strength (Fig. 7B-G). Three alleles exhibit equally severe reductions in dorsal mesodermal D-MEF2 expression, including $h t l^{A B 42}$ (Fig. 7C), $h t l^{A B 111}$ (Fig. 7D), and $h t l^{A D 326}$ (Fig. 7E). This strong phenotype can be understood in terms of the predicted severities of the corresponding molecular lesions, as described above. However, it is noteworthy that even in these mutants, there are a few D-MEF2-expressing dorsal mesodermal cells. This finding is consistent with the previous indication that, in the absence of Htl activity, cells may be competent to migrate but not in a directed manner.

In contrast to the previous group of $h t l$ mutants, $h t l^{Z Z 81}$ has relatively greater expression of D-MEF2 in cardial and dorsal somatic muscle cells (Fig. 7F). This observation suggests that this mutant retains some residual receptor function but is nevertheless a strong hypomorph. This conclusion is consistent with the carboxy-terminal truncation of the protein encoded by $h t l^{Z Z 81} \cdot h t l^{Y Y 262}$ is the weakest allele, exhibiting only moderate loss of cardial cells and dorsal group myofibers (Fig. 7G). This weak, hypomorphic phenotype can be explained by the likely modest destabilizing effect of the $h t 1^{\text {YY262 }}$ mutation on FGF receptor structure.

The htl mutant phenotype is partially rescued by targeted mesodermal expression of an activated form of Ras1

RTKs, of which Htl is a subfamily member, transduce extracellular signals via a highly conserved pathway involving the small GTP-binding protein, Ras (Lowy and Willumsen 1993; van der Geer et al. 1994). In Drosophila, the Ras1 gene has been implicated in signaling by several different RTKs, including Sevenless (Simon et al. 1991; Fortini et al. 1992), Torso (Doyle and Bishop 1993; Lu et al. 1993), the EGF receptor (Diaz-Benjumea and Hafen 1994), and the Breathless FGF receptor (Reichman-Fried et al. 1994). We were interested in assessing whether Ras 1 also acts downstream of $\mathrm{Htl}$ in mediating early mesodermal cell migration. To this end, we employed the targeted ectopic expression system developed by Brand and Perrimon (1993) to express a constitutively active form of Rasl in the mesoderm of htl mutant embryos.

Two transgenes were separately introduced into a $h t l^{Z Z 81}$ mutant background (see Materials and Methods). One corresponds to a cDNA encoding an activated form of Rasl cloned downstream of Gal4-binding sites (X. Lu and N. Perrimon, unpubl.), and the other contains a Gal4 gene under control of the twi promoter (Greig and Akam 1993). When these two lines are crossed together, activated Rasl is expressed in the early mesoderm of both wild-type and $h t l$ mutant embryos. If Rasl normally functions downstream of $\mathrm{Htl}$, then activated Ras1 should be capable of bypassing the requirement for the FGF receptor. This result would be manifest by the development of dorsal mesodermal derivatives as a measure of the successful migration of mesodermal cells to the dorsal ectoderm that supplies a necessary inductive signal (Staehling-Hampton et al. 1994; Frasch 1995). The most reliable marker for this experiment proved to be Eve because it has a simple, dorsally restricted expression pattern that is totally absent from homozygous $h t t^{Z Z 81}$ embryos (Fig. 8A,C). Ectopic expression of activated Ras1 in a wild-type genetic background led to the marked overproduction of the segmentally repeated Eveexpressing cells (Fig. 8B). This effect is a manifestation of the involvement of Ras1 in signaling by another RTK, 

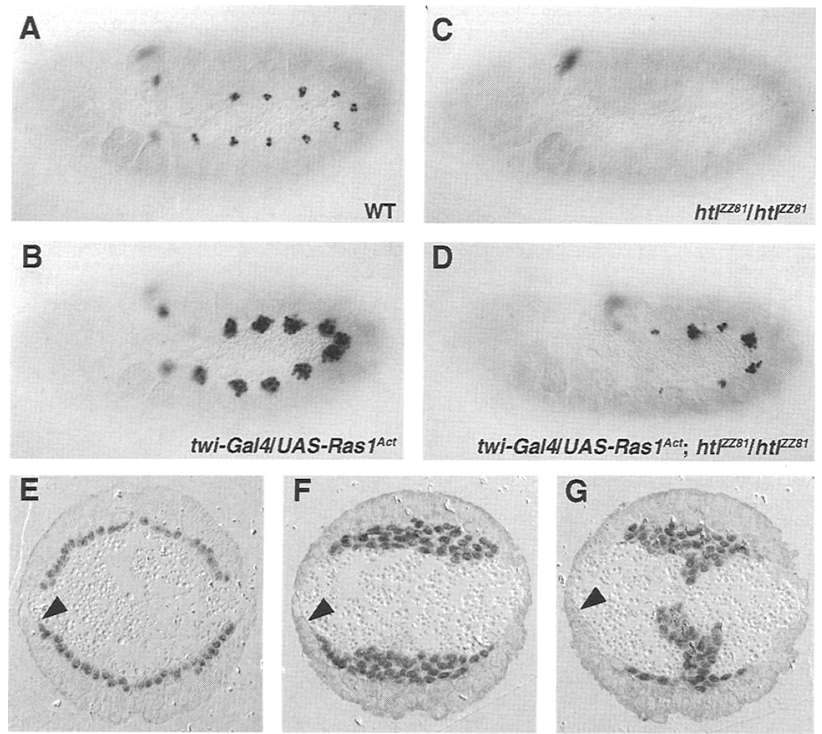

twi-Gal4/UAS-Ras $1^{\text {Act }}$
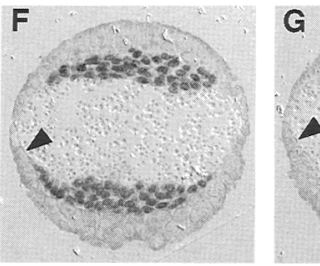

twi-Gal4/UAS-Ras $1^{A c t} ;\left.h t\right|^{2781} /\left.h t\right|^{2781}$

Figure 8. Partial rescue of the $h t l$ mutant phenotype by activated Ras1. Lateral views of stage 11 embryos are shown stained with an antibody directed against Eve. $(A)$ Wild type: Eve is normally expressed in the dorsal mesoderm at this stage in small, segmentally repeated clusters of cells. $(B)$ Expression of a constitutively active form of Rasl was targeted to the embryonic mesoderm of an otherwise wild-type embryo using the Gal4/UAS system (see Materials and Methods for details of the genetics). The Eve clusters are markedly enlarged but still retain their normal positions along the anteroposterior and dorsoventral axes. This effect is unrelated to the FGF receptor but is attributable to the involvement of another Ras-dependent pathway in mesodermal Eve cell fate specification (E. Buff, S. Gisselbrecht, and A.M. Michelson, unpubl.; see text). (C) In a homozygous $h t l^{Z Z 81}$ embryo, no Eve-expressing mesodermal cells develop. (D) Ectopic expression of activated Rasl in a homozygous $h t I^{Z Z 81}$ embryo generates a significant number of Eve-positive dorsal mesodermal cells. Some segments show no Eve expression, others have a wild-type number of Eve-positive cells, and others have expanded Eve clusters typical of the effect of activated Ras 1 in a wild-type genetic background. $(E-G)$ Transverse sections of Twist-stained embryos of the indicated genotypes. Arrowheads point to the dorsalmost ectoderm in each embyro. (E) Activated Rasl does not grossly affect mesodermal cell migration in a wild-type background. $(F)$ Twist-expressing cells migrate to the dorsal-most ectoderm under the influence of activated Rasl in one region of a $h t l$ mutant embryo. (G) In another region of the same mutant embryo, there is no apparent rescue of the mesodermal migration defect. The embryo in $E$ is slightly younger than that in $F$ and $G$. The latter is comparable in age to those shown in Fig. 6G-K.

the Drosophila EGF receptor, which is also essential for mesodermal Eve expression (E. Buff, S. Gisselbrecht, and A.M. Michelson, unpubl.). When activated Ras1 was expressed in the absence of $h t l$ function, partial rescue of the $h t l$ phenotype was observed (Fig. 8D). Some segments of the rescued embryos exhibit a nearly normal number of Eve-positive cells, some appear fully mutant, and others have an increased amount of Eve expression approaching that seen with activated Ras1 in a wild-type background.

Most significantly, the rescued Eve-expressing cells are confined entirely to the dorsal mesoderm, implying that activated Rasl is capable of at least partially inducing proper dorsolateral migration of the mesoderm in the absence of normal Htl FGF receptor function. This was assessed directly by examining the arrangement of Twist-positive cells in transverse sections of $h t l$ mutant embryos expressing activated Rasl. In some regions of such embryos, the mesodermal cell mass undergoes considerable spreading such that many cells reach all the way to the dorsal ectoderm (Fig. 8F). In other regions of the same embryo, the mesoderm shows minimal dorsolateral migration and appears indistinguishable from a htl mutant not expressing activated Rasl (Fig. 8G; cf. Fig. $6 \mathrm{H}-\mathrm{K}$ ). These findings are entirely consistent with the variability seen with the rescue of Eve expression (Fig. 6D). Of further interest, mesodermal expression of activated Ras 1 in an otherwise wild-type background did not grossly alter the overall arrangement of Twi-positive mesodermal cells (Fig. 8E). Collectively, the Eve and Twist expression data indicate that activated Rasl is capable of partially rescuing the mesodermal migration defect associated with loss of $h t l$ function.

Rescue of visceral mesoderm formation in htl mutant embryos by ectopic expression of Dpp

Failure of mesodermal cells to migrate toward the dorsal ectoderm in the absence of $h t l$ function prevents these cells from acquiring visceral and cardiac fates under the inductive influence of Dpp (Staehling-Hampton et al. 1994; Frasch 1995; see Discussion). To determine whether mesodermal cells deficient in Htl activity are nevertheless competent to form dorsal mesodermal derivatives, we ectopically expressed Dpp throughout the mesoderm in a $h t l$ mutant background. In wild-type embryos, such ectopic Dpp expression dorsalizes the mesoderm (Staehling-Hampton et al. 1994; Frasch 1995). This is manifest, for example, by the induction of bap expression at ventral and lateral levels of the mesoderm where this visceral mesodermal marker is never normally expressed (Staehling-Hampton et al. 1994; Fig. 9A,B). When Dpp was provided to the entire mesoderm of $h t l$ mutant embryos, bap transcription was activated all along the dorsoventral axis where mesodermal cells are found, including in the most ventral positions (Fig. 9D). However, the dorsal edge of this mesodermal bap domain had the typical irregular appearance of $h t l$ embryos secondary to incomplete dorsolateral migration of the mesoderm /cf. Figs. 5A-F and Figs. 9B,D). These findings demonstrate that the Htl-deficient mesoderm is competent to respond to Dpp in the specification of visceral mesodermal fates.

As described previously (Staehling-Hampton et al. 1994), ectopic Dpp induces bap expression in segmentally repeated stripes in otherwise wild-type embryos (Fig. 9B). This presumably reflects the input of segmentation genes to early mesodermal pattern formation. It is significant that in a htl mutant background these meso- 

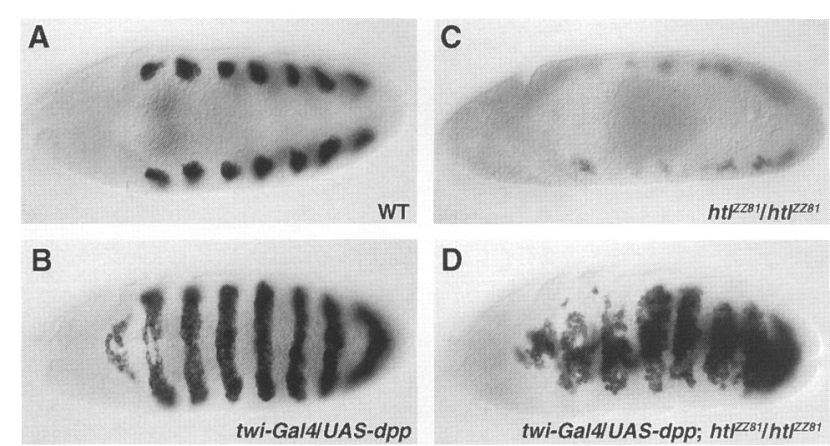

D

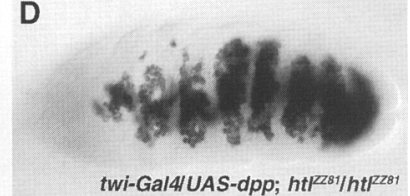

Figure 9. Induction of bap expression by Dpp in the absence of $h t l$ function. Ventral views of early stage 10 embryos stained for expression of bap transcripts. (A) bap is expressed solely in segmentally repeated patches of dorsal mesodermal cells in wildtype embryos at this developmental stage (cf. Fig. $4 C)$. $(B)$ When Dpp is expressed thoughout the mesoderm of an otherwise wildtype embryo under the influence of $t w i-G a l 4$, bap transcripts are induced along the entire dorsoventral axis but are restricted to segmentally repeated stripes. $(C)$ Dorsally restricted bap expression is markedly reduced in the absence of $h t l$ function (cf. Fig. 4G). (D) Ectopic Dpp induces bap expression at all dorsoventral levels in mesoderm that has undergone incomplete migration in the absence of $h t l$ function. However, the normally sharp anteroposterior boundaries of these bap stripes are lost during the stages of mesodermal spreading.

dermal stripes initiate correctly during gastrulation (data not shown), but then lose their characteristically sharp anteroposterior borders during the stages of mesodermal cell spreading (Fig. 9D). Thus, htl appears to be required for the correct positioning of mesodermal cells along both the anteroposterior and dorsoventral embryonic axes.

\section{Discussion}

\section{Htl FGF receptor activity is involved in early mesodermal cell migration}

The present work establishes that $h t 1$ encodes an FGF receptor that is essential in the germ band extending Drosophila embryo for the proper directed migration of mesodermal cells along the inner surface of the ectoderm. Formation of the mesoderm by the inward movement of ventral blastoderm cells is not dependent on $h t l$ function, nor does the subsequent proliferation of these cells require $\mathrm{Htl}$ activity. The most striking feature of the htl mutant phenotype is that the invaginated mesodermal cells initially remain aggregated and fail to spread correctly in a dorsolateral direction. There is also an associated loss of correct positioning of mesodermal cells along the anteroposterior axis of the embryo. These early migration defects lead to subsequent failure to form the heart, visceral mesoderm, and the complete complement of body wall muscles.

Mesodermal cells in htl mutant embryos are not completely immobile because they can be found at various positions along the lateral ectoderm and even deep within the yolk cavity (Fig. 6). In addition, occasional somatic muscle and cardiac cells are present in the dorsal mesoderm of null $h t l$ alleles (Figs. 2 and 7), consistent with random movement allowing rare cells to reach the dorsal ectoderm. These findings suggest that Htl specifically contributes to directional cell migration and not to a more general aspect of cell motility. A similar function has been described for a $C$. elegans FGF receptor that is involved in sex myoblast migration (Devore et al. 1995).

There are several possible mechanisms whereby a RTK could provide guidance for cell movements. In one model, the receptor might respond directly to a chemotactic signal emanating from neighboring cells. This could represent a graded concentration of ligand secreted by the overlying ectoderm and toward which mesodermal cells would be attracted. Such a mechanism is operative in vertebrates in the migration of myogenic precursors from the somites to the limbs (Bladt et al. 1995). The c-kit and PDGF $\beta$ RTKs also mediate directed cell migration by a chemotactic mechanism (Blume-Jensen et al. 1991; Kundra et al. 1994).

One prediction of the chemoattractant gradient hypothesis is that a constitutively active receptor or intermediate signal transducer should eliminate the critical graded output by bypassing the involvement of the ligand. However, when an activated form of Rasl was expressed uniformly throughout the mesoderm of $h t l$ mutant embryos, dorsal mesodermal cell migration was partially rescued without an overall disruption of this process. Furthermore, forced expression of activated Rasl in the mesoderm of wild-type embryos did not induce the aberrant movement of early ventral mesodermal cells. This suggests that a graded response is not essential for $\mathrm{Htl}$ function, although subtle disturbances of such a mechanism may not have been detected in our phenotypic analyses. It is also possible that additional migratory effects of Htl could be mediated by signal transducers other than Rasl. Similar observations have been made for deregulated activity of Breathless, the other known Drosophila FGF receptor, which is involved in tracheal, glial, and follicle cell migration (Klambt et al. 1992; Reichman-Fried et al. 1994; Murphy et al. 1995).

Integration between adhesion and growth factor receptor signaling pathways plays a critical role in the regulation of many cellular processes, including directed cell migration (Huttenlocher et al. 1995; Schwartz et al. 1995). Thus, another way in which RTK activity might control cell movement is to alter the adhesion of motile cells to spatially restricted external guidance cues. Axonal pathfinding in the nervous system relies on such a mechanism (Goodman and Shatz 1993), and at least one RTK has been shown to play a role in such events (Callahan et al. 1995). Alternatively, FGF receptors might mediate signals provided directly or indirectly by cell adhesion molecules (Green et al. 1996).

A RTK also could affect cell movement by controlling the self-adhesive properties of migratory cells. For example, by promoting the dissociation of such cells, the RTK could indirectly influence their capacity to move in re- 
sponse to another stimulus. In this context, it is noteworthy that mesodermal cells deficient in $\mathrm{Htl}$ activity appear to remain aggregated at a time when their wildtype counterparts already have begun to spread along the ectoderm. Finally, it is possible that $\mathrm{Htl}$ could induce changes in the transcription of those genes whose products are involved in cell migration. These various modes of action are not mutually exclusive, and it is conceivable that some combination of mechanisms may mediate the mesoderm-specific effects of $\mathrm{Htl}$.

\section{Rasl acts downstream of htl}

An activated form of Rasl partially rescues the mesoderm migration defect associated with loss of $h t l$ function. As a result of the partially restored mesodermal spreading stimulated by activated Rasl, Eve is induced in the dorsal mesoderm of $h t l$ mutant embryos by ectodermally derived Dpp. Thus, Rasl appears to be an important downstream mediator of $\mathrm{Htl}$ signaling. This conclusion is consistent with a more general involvement of Ras in signal transduction by a wide variety of RTKs (Lowy and Willumsen 1993; van der Geer et al. 1994), including many found in Drosophila (Simon et al. 1991; Fortini et al. 1992; Doyle and Bishop 1993; Lu et al. 1993; Diaz-Benjumea and Hafen 1994; Reichman-Fried et al. 1994) and those mediating cell migration in other systems (Sosnowski et al. 1993; Kundra et al. 1994; Reichman-Fried et al. 1994; Devore et al. 1995; Lee et al. 1996). It is not yet clear whether additional members of the signaling cascade that commonly act in concert with Ras also are used by Htl. For example, both Raf-dependent and Raf-independent mechanisms function downstream of Ras in different instances of RTK-mediated cell migration in Drosophila (Reichman-Fried et al. 1994; Lee et al. 1996).

The ability of Rasl to only partially substitute for $\mathrm{Htl}$ in facilitating dorsal mesodermal cell migration can be explained in two ways. First, it is possible that our targeted ectopic expression system fails to completely mimic the endogenous activation of Rasl by Htl. This could be attributable to a suboptimal level of activated Rasl expression, an improper spatial expression pattern of this factor, and/or a failure to duplicate the correct temporal occurrence of this signal. Second, Ras 1 may not be the sole transducer of the migration signal mediated by $\mathrm{Htl}$. Branching signal transduction pathways have been described for other RTKs (van der Geer et al. 1994), including those that mediate cell migration (ReichmanFried et al. 1994; DeVore et al. 1995).

\section{Role of the ectoderm in inducing mesodermal cell fates}

$\mathrm{Htl}$ is required for the normal dorsolateral migration of the earliest population of mesodermal cells. Failure of these cells to reach the dorsal ectoderm can explain most of the later defects seen in $h t l$ mutant embryos. Induction of cardiac and visceral mesodermal fates is dependent on Dpp, a TGF $\beta$ family member that diffuses to the mesoderm from the dorsal ectoderm (Staehling-Hampton et al. 1994; Frasch 1995). Dorsal somatic muscle fate also requires the activity of Dpp (A.M. Michelson and S. Gisselbrecht, unpubl.). Thus, if mesodermal cells do not reach the dorsally restricted domain of Dpp expression, all of these derivatives will fail to be induced in $h t l \mathrm{mu}-$ tants. Similar observations were made in two other experimental paradigms in which contact between the mesoderm and dorsal ectoderm was limited (Baker and Schubiger 1995; Maggert et al. 1995). It is also noteworthy that our ectopic Dpp expression experiment revealed that mesodermal cells are competent to respond to this growth factor even in the absence of Htl function; that is, $\mathrm{Htl}$ itself is not involved directly in the induction of visceral mesodermal cell fate.

A prominent feature of the $h t l$ mutant phenotype is the loss of somatic muscles in ventral and lateral as well as dorsal regions of the embryo. Even this defect can be ascribed to a cell migration problem because additional abnormalities of mesodermal cell positioning along the anteroposterior embryonic axis were identified at all dorsoventral levels (Fig. 9). Thus, failure of prospective muscle progenitors to acquire position-specific inductive cues could account for muscle loss not only from dorsal but also from ventral and lateral groups. The apparent randomness of mesodermal cell movements also can explain the variable distribution of missing muscles in all regions of $h t l$ mutant embryos.

Dpp acts as a morphogen in patterning the dorsoventral axis of the Drosophila embryo (Ferguson and Anderson 1992; Wharton et al. 1993). Thus, amnioserosa and specific ectodermal cell fates are established at different threshold levels of a Dpp activity gradient. Because Dpp also induces visceral and cardiac mesodermal fates by acting across germ layers (Staehling-Hampton et al. 1994; Frasch 1995), does the ectodermal Dpp activity gradient influence mesoderm development? One aspect of the htl mutant phenotype suggests that this may be the case. Loss of $h t l$ function causes a greater reduction in cardiac than in visceral mesodermal cells. Given that the dorsal defects in $h t l$ mutants can be attributed to a failure of proper mesodermal cell migration into the Dpp domain, the more severe loss of heart precursors suggests that a higher level of Dpp activity may be required for cardiogenesis. This hypothesis is consistent with the observation that cardiac cells derive from the most dorsal region of the mesoderm (Dunin-Borkowski et al. 1995) where Dpp activity is highest (Ferguson and Anderson 1992; Wharton et al. 1993). Similarly, if a lower Dpp threshold specifies visceral mesodermal fates, significantly more cells would be expected to reach this more lateral level of the Dpp activity gradient in htl mutant embryos.

\section{FGF receptor signaling in mesoderm development}

FGF receptors have evolved multiple functions in the development of the mesoderm and its derivatives. In $\mathrm{Xe}$ nopus, FGF signaling plays a critical early role in mesoderm induction (Amaya et al. 1991; Cornell et al. 1995), 
whereas mouse FGFR-1 is essential for mesodermal patterning but not for the formation of this germ layer (Deng et al. 1994; Yamaguchi et al. 1994). Interestingly, some aspects of the fgfr-1 mutant phenotype can be explained by a defect in mesodermal cell migration from the primitive streak (Yamaguchi et al. 1994). Involvement of FGF receptor signaling in cell migration is emerging as a recurring theme, particularly in mesodermal development (Deng et al. 1994; Yamaguchi et al. 1994; DeVore et al. 1995; Itoh et al. 1996; this work).

As is the case for murine FGFR-1, the Drosophila Htl FGF receptor is involved in patterning but not in early specification of the embryonic mesoderm. In the absence of $h t l$ function, mesodermal cells fail to migrate to their proper positions, and, as a result, do not receive the later inductive signals that are essential for their commitment to somatic, visceral, and cardiac fates. FGF receptor signaling in Drosophila thus provides a crucial link between the establishment of general mesodermal cell fate at gastrulation and the subsequent induction of lineage-specific identities by other signaling pathways.

\section{Materials and methods}

Fly strains and genetic techniques

A genetic screen employing EMS mutagenesis of an isogenic third chromosome marked with red and ebony $(e)$ was undertaken essentially as described by Seeger and coworkers (Seeger et al. 1993). Lethal third chromosome mutations were recovered over a TM3 balancer containing a fushi tarazu (ftz)-LacZ transgene. Initial phenotypic screening was for lines in which Eve expression was aberrant in the central nervous system and/or the mesoderm.

Targeted ectopic expression of an activated form of Ras l (containing a glycine to glutamine change at amino acid position 13 (X. Lu, pers. comm.) was achieved using the Gal4/UAS system (Brand and Perrimon 1993). A UAS-Ras $1^{\text {Act }}$ transgene inserted on the second chromosome (generously provided by $\mathrm{X}$. Lu and N. Perrimon, Harvard Medical School, Boston, MA/ was introduced into a $h t l^{Z Z 81}$ mutant background by standard genetic crosses to yield a line of the genotype, UAS $-R a s 1^{A c t} / \mathrm{CyO}, \mathrm{ftz}-$ $L a c Z ; h t 1^{Z Z 81} / \mathrm{TM} 6 \mathrm{~B}, a b d A-L a c Z$. Similarly, a twi-Gal4 insertion on the second chromosome (Greig and Akam 1993) was combined with a $h t l^{Z Z 81}$ third chromosome to yield a stock of

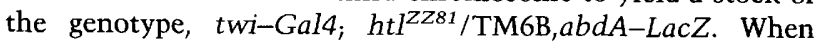
these two lines are crossed together, one eighth of the embryos are homozygous for the $h t l$ mutation and express Ras $1^{\text {Act }}$ throughout the mesoderm. These embryos can be identified by the absence of $L a c Z$ expression directed by the balancer chromosomes. An identical strategy using a UAS - $d p p$ transgene insertion on the second chromosome (Staehling-Hampton et al. 1994) was used to target expression of Dpp to the mesoderm of $h t 1^{Z Z 81}$ mutant embryos. Oregon $\mathrm{R}$ was used as the reference wild-type stock. All flies were grown on standard yeast-cornmeal agar medium at $25^{\circ} \mathrm{C}$.

\section{Immunohistochemical staining and in situ hybridization of embryos}

Embryos were collected on molasses agar plates at $25^{\circ} \mathrm{C}$, aged for the requisite times, and fixed with $4 \%$ formaldehyde, as described previously (Michelson et al. 1990; Michelson 1994). Antibody staining was carried out as described (Michelson
1994), using antibodies at the following dilutions: rabbit polyclonal $\alpha$-Eve (1:5000), $\alpha$-myosin heavy chain (1:500), $\alpha$-Kruppel (1:1500), $\alpha$-DMEF2 (1:1500), $\alpha$ - $\beta$-galactosidase (Cappel, 1:500), and $\alpha$-Twist $(1: 10,000)$; rat polyclonal, affinity-purified $\alpha$-Nau (1:50); mouse monoclonal $\alpha$-Fasciclin III $\langle 1: 3\rangle, \alpha$ - $\beta$-galactosidase (Promega; 1:500), and $\alpha$-pericardial cell antigen (1:3). Markers used to analyze the central nervous system in htl mutant embryos included mouse mAb $22 \mathrm{Cl0}(1: 10)$, mouse $\alpha$-RK2 (1:5), mouse $\alpha$-Engrailed $(1: 5)$, and rabbit $\alpha$-Eve (as above). Biotinylated secondary antibodies (Vector Laboratories) were preadsorbed against an overnight collection of embryos and used at a dilution of 1:500. In situ hybridization of embryos was carried out using digoxigenin-labeled DNA probes (Tautz and Pfeifle 1989), as modified by Michelson et al. (1990). Alternatively, RNA probes were used for embryo in situ hybridizations, as described (O'Neill and Bier 1994).

Embryos were photographed under Nomarski optics on a Zeiss Axiophot microscope using Kodak EPT160 slide film. Slides $(35-\mathrm{mm})$ were scanned and only the contrast, brightness, and color balance of these digital images subsequently were manipulated using Adobe Photoshop.

\section{Quantitation of muscle defects}

The numbers of $\mathrm{Kr}$-expressing dorsal (DAl or DO1), lateral (LL1), and ventral (VA2) muscle precursors were counted in 28 individual stage 13-14 $h t I^{A B 42}$ mutant embryos. Abdominal segments 1-7 were examined on both sides of each embryo ( $n=392$ hemisegments). The mean percentage ( \pm S.D.) of muscle precursors present per embryo was calculated (number observed/number expected).

\section{Embryo sectioning}

Embryos were embedded in Spurr resin (Spurr Low Viscosity Embedding Medium, Polysciences) prior to sectioning. In brief, darkly stained embryos were dehydrated through an ethanol series, washed twice in $100 \%$ ethanol, infiltrated overnight with a mixture of Spurr medium and propylene oxide $\{1: 1)$, and finally incubated for several hours in $100 \%$ Spurr medium at room temperature. Embryos were then aligned in embedding molds in an orientation suitable for transverse sectioning and the resin was allowed to harden overnight at $65^{\circ} \mathrm{C}$. Serial $5-\mu \mathrm{m}$ sections were cut from the resulting blocks using a Leica microtome fitted with a tungsten carbide blade (Energy Beam Sciences), adhered to coated microscope slides (Fisher Superfrost Plus), cleared by application of immersion oil and examined under Nomarski optics, as described above.

\section{Preparation of embryo DNA}

Flies bearing balanced $h t l$ alleles were outcrossed to an Oregon $\mathrm{R}$ stock and embryos were collected from matings between the resulting $h t l /+$ adults. These embryos were incubated until all viable progeny had hatched $\left(\sim 24 \mathrm{hr}\right.$ at $\left.25^{\circ} \mathrm{C}\right)$. Fifty of the unhatched homozygous $h t l$ mutant embryos were crushed in 200 $\mu l$ extraction buffer ( $10 \mathrm{~mm}$ Tris at pH 8.2, 1 mM EDTA, $25 \mathrm{~mm}$ $\mathrm{NaCl}, 200 \mu \mathrm{g} / \mathrm{ml}$ proteinase $\mathrm{K}$ freshly diluted from a frozen 20 $\mathrm{mg} / \mathrm{ml}$ stock), incubated at $37^{\circ} \mathrm{C}$ for $30 \mathrm{~min}$, and boiled for 10 min. Particulate material was removed from the crude extract by spinning for $5 \mathrm{~min}$ at top speed in a microcentrifuge. The supernatant was used as a source of genomic DNA for polymerase chain reactions without further processing. 


\section{SSCP analysis}

The approximate site of each of the $h t l$ mutations was determined by SSCP analysis of genomic DNA isolated from the mutant lines (Orita et al. 1989). Fifteen pairs of oligonucleotide primers were used to generate overlapping PCR products of 250 bp or less that span the entire DFR1/htl coding sequence (Shishido et al. 1993; primer sequences available on request). Genomic DNAs from three different strains were used as controls: Oregon R, red e (the parental strain employed in the EMS mutagenesis screen), and another lethal-bearing mutant line from the screen that complemented the $h t l$ alleles. Primer pairs were $5^{\prime}$ end-labeled with T4 polynucleotide kinase and $\left[\gamma^{-32} \mathrm{P}\right] \mathrm{ATP}(6000 \mathrm{Ci} / \mathrm{mmole})$, and then were supplemented with a 2.5-fold excess of the same unlabeled primers. Hot-start PCR reactions were performed in $12 \mu \mathrm{l}$ total volume containing $1 \mu \mathrm{l}$ of denatured embryonic genomic DNA as template (see above), $200 \mathrm{~nm}$ each primer, $200 \mu \mathrm{M}$ each dNTP, and $0.2 \mu \mathrm{l}$ of Expand High Fidelity thermostable DNA polymerase mixture (Boehringer Mannheim). PCR amplification was carried out for 28 cycles, as follows: $1 \mathrm{~min}$ at $94^{\circ} \mathrm{C}, 1 \mathrm{~min}$ at $55^{\circ} \mathrm{C}$, and $1 \mathrm{~min}$ at $72^{\circ} \mathrm{C}$. A $2-\mu \mathrm{l}$ aliquot of each PCR reaction was combined with 4 $\mu 1$ of denaturation buffer $(95 \%$ formamide, $0.05 \%$ bromophenol blue, $0.05 \%$ xylene cyanol, $20 \mathrm{~mm}$ EDTA), incubated at $95^{\circ} \mathrm{C}$ for $5 \mathrm{~min}$ and then chilled on ice. Samples were loaded on $5 \%$ nondenaturing polyacrylamide gels and run in $0.5 \times$ Peacock's buffer at $4^{\circ} \mathrm{C}$ for $2 \mathrm{hr}$ at $40 \mathrm{~W}$ constant power. Gels were dried onto filter paper without fixation and exposed to X-ray film.

\section{Cloning and sequence analysis}

The complete htl coding region was PCR-amplified from the genomic DNA of all htl mutant alleles and from the red $e$ parental strain using the following oligonucleotides as primers: 5'-GGGAATTCATATACCAAAAATGGCTGCCGCCTG-3' and 5'-ACGTCTCGAGACCAAGTGTTTGGTCCGAACTTAACAGGAC-3'. These primers correspond to nucleotides 54-78 and 2309-2280 of the published DFR1 sequence, respectively; the italicized nucleotides were added to introduce EcoRI and $X$ hoI restriction sites. PCR amplification was for 30-40 cycles, as follows: $1 \mathrm{~min}$ at $94^{\circ} \mathrm{C}, 1 \mathrm{~min}$ at $60^{\circ} \mathrm{C}$, and $3 \mathrm{~min}$ at $72^{\circ} \mathrm{C}$. The amplified DNAs were digested with EcoRI plus $X$ hol and cloned into the polylinker of pSP73 (Promega). Sequences of the cloned inserts were determined on both strands using an ABI automated sequencer (primer sequences available on request). The complete wild-type coding region was sequenced from three independent PCR reactions, whereas for each of the $h t l$ alleles (with the exception of $h t t^{A B 42}$ which was sequenced in its entirety), only the region that demonstrated variation by SSCP analysis was sequenced. All mutations were confirmed by sequencing the mutant $h t l$ genes cloned from at least two independent PCR amplifications.

\section{Acknowledgments}

We thank Jacob Harrison and Shannon MacDonald for excellent and invaluable technical assistance, and Karen Lolans and Pablo Perez for maintenance of fly stocks. We also are grateful to Lizabeth Perkins, Norbert Perrimon, Xiangyi Lu, Michael Akam, Michael Hoffmann, and Kathy Matthews in the Bloomington Stock Center for providing fly lines, and to Manfred Frasch, Maria Leptin, Siegfried Roth, Christine Rushlow, Dan Kiehart, Rolf Bodmer, Susan Abmayr, Talila Volk, Bruce Paterson, Corey Goodman, Seymour Benzer, Andrew Tomlinson, and Nipam Patel for antibodies and cDNAs. We would like to acknowledge David Beier for his encouragement and guidance in the SSCP analysis, and Donald Morisato for sharing his expertise in embryo sectioning. Peter Rahaim and Cara Ruble provided expert assistance with DNA sequencing. We thank Norbert Perrimon, David Van Vactor, Jon Epstein, and Jacob Harrison for insightful comments on the manuscript. Finally, we appreciate the willingness of Benny Shilo and Talila Volk to generously share with us the results of their independent $h t l$ studies prior to publication. J.B.S. was supported by the Cancer Research Fund of the Damon Runyon-Walter Winchell Foundation (fellowship DRG-1279). A.M.M. and C.Q.D. are both Assistant Investigators of the Howard Hughes Medical Institute.

The publication costs of this article were defrayed in part by payment of page charges. This article must therefore be hereby marked "advertisement" in accordance with 18 USC section 1734 solely to indicate this fact.

\section{References}

Amaya, E., T.J. Musci, and M.W. Kirschner. 1991. Expression of a dominant negative mutant of the FGF receptor disrupts mesoderm formation in Xenopus embryos. Cell 66: 257270 .

Azpiazu, N. and M. Frasch. 1993. tinman and bagpipe - Two homeobox genes that determine cell fates in the dorsal mesoderm of Drosophila. Genes \& Dev. 7: 1325-1340.

Baker, R. and G. Schubiger. 1995. Ectoderm induces musclespecific gene expression in Drosophila embryos. Development 121: 1387-1398.

Bate, M. 1993. The mesoderm and its derivatives. In The development of Drosophila melanogaster (ed. M. Bate and A. Martinez Arias\}, pp. 1013-1090. Cold Spring Harbor Laboratory Press, Cold Spring Harbor, NY.

Baylies, M.K. and M. Bate. 1996. Twist: A myogenic switch in Drosophila. Science 272: 1481-1484.

Baylies, M.K., A.M. Arias, and M. Bate. 1995. wingless is required for the formation of a subset of muscle founder cells during Drosophila embryogenesis. Development 121: 38293837.

Beer, I., G. Technau, and J. Campos Ortega. 1987. Lineage analysis of transplanted individual cells in embryos of Drosophila melanogaster. IV. Commitment and proliferative capabilities of individual mesodermal cells. Roux's Arch. Dev. Biol. 196: 222-230.

Bellen, H.J., H. Vaessin, E. Bier, A. Kolodkin, D. D'Evelyn, S. Kooyer, and Y.N. Jan. 1992. The Drosophila couch potato gene: An essential gene required for normal adult behavior. Genetics 131: 365-375.

Bladt, F., D. Riethmacher, S. Isenmann, A. Aguzzi, and C. Birchmeier. 1995. Essential role for the c-met receptor in the migration of myogenic precursor cells into the limb bud. $\mathrm{Na}$ ture 367: 768-771.

Blume-Jensen, P., L. Claesson-Welsh, A. Siegbahn, K.M. Zsebo, B. Westermark, and C.-H. Heldin. 1991. Activation of the human $c$-kit product by ligand-induced dimerization mediates circular actin reorganization and chemotaxis. EMBO $\mathrm{J}$. 10: 4121-4128.

Bodmer, R. 1993. The gene tinman is required for specification of the heart and visceral muscles in Drosophila. Development 118: 719-729.

Bossemeyer, D. 1994. The glycine-rich sequence of protein kinases: A multifunctional element. Trends Biochem. Sci. 19: 201-205.

Bour, B.A., M.A. O'Brien, W.L. Lockwood, E.S. Goldstein, R. Bodmer, P.H. Taghert, S.M. Abmayr, and H.T. Nguyen. 1995. Drosophila MEF2, a transcription factor that is essen- 
tial for myogenesis. Genes \& Dev. 9: 730-741.

Brand, A.H. and N. Perrimon. 1993. Targeted gene expression as a means of altering cell fates and generating dominant phenotypes. Development 118: 401-415.

Callahan, C.A., M.G. Muralldhar, S.E. Lundgren, A.L. Scully, and J.B. Thomas. 1995. Control of neuronal pathway selection by a Drosophila receptor protein-tyrosine kinase family member. Nature 376: 171-174.

Cornell, R.A., T.J. Musci, and D. Kimelman. 1995. FGF is a prospective competence factor for early activin-type signals in Xenopus mesoderm induction. Development 121: 24292437.

DeLaPompa, J.L., J.R. Garcia, and A. Ferrus. 1989. Genetic analysis of muscle development in Drosophila melanogaster. Dev. Biol. 131: 439-454.

Deng, C.-X., A. Wynshaw-Boris, M.M. Shen, C. Daugherty, D.M. Ornitz, and P. Leder. 1994. Murine FGFR-1 is required for early postimplantation growth and axial organization. Genes \& Dev. 8: 3045-3057.

Devore, D.L., H.R. Horvitz, and M.J. Stern. 1995. An FGF receptor signaling pathway is required for the normal cell migrations of the sex myoblasts in C. elegans hermaphrodites. Cell 83: 611-620.

Diaz-Benjumea, F.J. and E. Hafen. 1994. The Sevenless signalling cassette mediates Drosophila EGF receptor function during epidermal development. Development 120: 569-578.

Doyle, H.J. and J.M. Bishop. 1993. Torso, a receptor tyrosine kinase required for embryonic pattern formation, shares substrates with the Sevenless and EGF-R pathways in Drosophila. Genes \& Dev. 7: 633-646.

Dunin Borkowski, O.M., N.H. Brown, and M. Bate. 1995. Anterior-posterior subdivision and the diversification of the mesoderm in Drosophila. Development 121: 4183-4193.

Ferguson, E.L. and K.V. Anderson. 1992. decapentaplegic acts as a morphogen to organize dorsal-ventral pattern in the Drosophila embryo. Cell 71: 451-461.

Fortini, M.E., M.A. Simon, and G.M. Rubin. 1992. Signalling by the Sevenless protein tyrosine kinase is mimicked by Ras 1 activation. Nature 355: 559-561.

Frasch, M. 1995. Induction of visceral and cardiac mesoderm by ectodermal Dpp in the early Drosophila embryo. Nature 374: 646-467.

Frasch, M., T. Hoey, C. Rushlow, H. Doyle, and M. Levine. 1987. Characterization and localization of the Even-skipped protein of Drosophila. EMBO I. 6: 749-759.

Gaul, U., E. Seifert, R. Schuh, and H. Jackle. 1987. Analysis of Kruppel protein distribution during early Drosophila development reveals posttranscriptional regulation. Cell 50: 639647.

Goodman, C.S. and C.J. Shatz. 1993. Developmental mechanisms that generate precise patterns of neuronal connectivity. Cell 72: 77-98.

Green, P.J., F.S. Walsh, and P. Doherty. 1996. Promiscuity of fibroblast growth factor receptors. Bioessays 18: 639-646.

Greig, S. and M. Akam. 1993. Homeotic genes autonomously specify one aspect of pattern in the Drosophila mesoderm. Nature 362: 630-632.

Hanks, S.K. and T. Hunter. 1995. The eukaryotic protein kinase superfamily: Kinase (catalytic) domain structure and classification. FASEB 9: 576-596.

Huttenlocher, A., R.R. Sandborg, and A.F. Horwitz. 1995. Adhesion in cell migration. Curr. Opin. Cell Biol. 7: 697-706.

Ip, Y.T., R.E. Park, D. Kosman, K. Yazdanbakhsh, and M Levine. 1992. dorsal-twist interactions establish snail expression in the presumptive mesoderm of the Drosophila embryo. Genes \& Dev. 6: 1518-1530.
Itoh, N., T. Mima, and T. Mikawa. 1996. Loss of fibroblast growth factor receptors is necessary for terminal differentiation of embryonic limb muscle. Development 122: 291300.

Jiang, J., D. Kosman, Y.T. Ip, and M. Levine. 1991. The dorsal morphogen gradient regulates the mesoderm determinant twist in early Drosophila embryos. Genes \& Dev. 5: 18811891 .

Kam, Z., J.S. Minden, D.A. Agard, J.W. Sedat, and M. Leptin. 1991. Drosophila gastrulation: Analysis of cell shape changes in living embryos by three-dimentional fluorescence microscopy. Development 112: 365-370.

Klambt, C., L. Glazer, and B.-Z. Shilo. 1992. Breathless, a Drosophila FGF receptor homolog, is essential for migration of tracheal and specific midline glial cells. Genes \& Dev. 6: $1668-1678$.

Kundra, V., J.A. Escobedo, A. Kazlauskas, H.K. Kim, S.G. Rhee, L.T. Williams, and B.R. Zetter. 1994. Regulation of chemotaxis by the platelet-derived growth factor receptor- $\beta$. $\mathrm{Na}$ ture 367: 474-476.

Lee, T., L. Feig, and D.J. Montell. 1996. Two distinct roles for Ras in a developmentally regulated cell migration. Development 122: 409-418.

Leptin, M. and B. Grunewald. 1990. Cell shape changes during gastrulation in Drosophila. Development 110: 73-84.

Leptin, M., J. Casal, B. Grunewald, and R. Reuter. 1992. Mechanisms of early Drosophila mesoderm formation. Development (Suppl.): 23-31.

Lilly, B., B. Zhao, G. Ranganayakulu, B.M. Paterson, R.A Schultz, and E.N. Olson. 1995. Requirement of MADS domain transcription factor D-MEF2 for muscle formation in Drosophila. Science 267: 688-693.

Lowy, D.R. and B.M. Willumsen. 1993. Function and regulation of Ras. Annu. Rev. Biochem. 62: 851-891.

Lu, X., T.-B. Chou, N.G. Williams, T. Roberts, and N. Perrimon 1993. Control of cell fate determination by $\mathrm{p} 21^{\text {ras }} / \mathrm{Ras} 1$, an essential component of torso signaling in Drosophila. Genes \& Dev. 7: 621-632.

Maggert, K., M. Levine, and M. Frasch. 1995. The somatic-visceral subdivision of the embryonic mesoderm is initiated by dorsal gradient thresholds in Drosophila. Development 121: 2107-2116.

Michelson, A.M. 1994. Muscle pattern diversification in Drosophila is determined by the autonomous function of homeotic genes in the embryonic mesoderm. Development 120: $755-768$

Michelson, A.M., S.M. Abmayr, M. Bate, A. Martinez Arias, and T. Maniatis. 1990. Expression of a MyoD family member prefigures muscle pattern in Drosophila embryos. Genes \& Dev. 4: 2086-2097.

Mohammadi, M., J. Schlessinger, and S.R. Hubbard. 1996. Structure of the FGF receptor tyrosine kinase domain reveals a novel autoinhibitory mechanism. Cell 86: 577-587.

Morisato, K. and K.V. Anderson. 1995. Signaling pathways that establish the dorsal-ventral pattern of the Drosophila embryo. Annu. Rev. Genet. 29: 371-399.

Murphy, A.M., T. Lee, C.M. Andrews, B.-Z. Shilo, and D.J. Montell. 1995. The Breathless FGF receptor homolog, a downstream target of Drosophila C/EBP in the developmental control of cell migraton. Development 121: 2255-2263.

O'Neill, J.W. and E. Bier. 1994. Double-label in situ hybridization using biotin and digoxigenin-tagged RNA probes. Biotechniques 17: 870-875.

Orita, M., H. Iwahana, H. Kanazawa, K. Hayashi, and T. Sekiya. 1989. Detection of polymorphisms of human DNA by gel electrophoresis as single-strand conformation polymor- 
phisms. Proc. Natl. Acad. Sci. 86: 2766-2770.

Pan, D., J.-D. Huang, and A.J. Courey. 1991. Functional analysis of the Drosophila twist promoter reveals a dorsal-binding ventral activator region. Genes \& Dev. 5: 1892-1901.

Paterson, B.M., U. Walldorf, J. Eldridge, A. Dubendorfer, M. Frasch, and W.J. Gehring. 1991. The Drosophila homologue of vertebrate myogenic-determination genes encodes a transiently expressed nuclear protein marking primary myogenic cells. Proc. Natl. Acad. Sci. 88: 3782-3786.

Ranganayakulu, G., B. Zhao, A. Dokidis, J.D. Molkentin, E.N. Olson, and R.A. Schulz. 1995. A series of mutations in the D-MEF2 transcription factor reveal multiple functions in larval and adult myogenesis in Drosophila. Dev. Biol. 171: 169-181.

Ranganayakulu, G., R.A. Schulz, and E.N. Olson. 1996. Wingless signaling induces nautilus expression in the ventral mesoderm of the Drosophila embryo. Dev. Biol. 176: 143-148.

Reichman-Fried, M., B. Dickson, E. Hafen, and B.-Z. Shilo. 1994. Elucidation of the role of Breathless, a Drosophila FGF receptor homolog, in tracheal cell migration. Genes \& Dev. 8: $428-439$.

Schwartz, M.A., M.D. Schaller, and M.H. Ginsberg. 1995. Integrins: Emerging paradigms of signal transduction. Annu. Rev. Cell Dev. Biol. 11: 549-599.

Seeger, M., G. Tear, D. Ferres-Marco, and C.S. Goodman. 1993. Mutations affecting growth cone guidance in Drosophila: Genes necessary for guidance toward or away from the midline. Neuron 10: 409-426.

Shishido, E., S. Higashijima, Y. Emori, and K. Saigo. 1993. Two FGF-receptor homologues of Drosophila-One is expressed in mesodermal primordium in early embryos. Development 117: 751-761.

Simon, M.A., D.D.L. Bowtell, G.S. Dodson, T.R. Laverty, and G.M. Rubin. 1991. Ras1 and a putative guanine nucleotide exchange factor perform crucial steps in signaling by the Sevenless protein tyrosine kinase. Cell 67: 701-716.

Simpson, P. 1983. Maternal-zygotic gene interactions during formation of the dorsoventral pattern in Drosophila embryos. Genetics 105: 615-632.

Sosnowski, R.G., S. Feldman, and J.R. Feramisco. 1993. Interference with endogenous Ras function inhibits cellular responses to wounding. J. Cell Biol. 121: 113-119.

Staehling-Hampton, K., F.M. Hoffmann, M.K. Baylies, E. Rushton, and M. Bate. 1994. dpp induces mesodermal gene expression in Drosophila. Nature 372: 783-786.

Sweeton, D., S. Parks, M. Costa, and E. Wieschaus. 1991. Gastrulation in Drosophila the formation of the ventral furrow and posterior midgut invaginations. Development 112: 775789.

Tautz, D. and C. Pfeifle. 1989. A nonradioactive in situ hybridization method for the localization of specific RNAs in Drosophila embryos reveals a translational control of the segmentation gene hunchback. Chromosoma 98: 81-85.

Taylor, M.V., K.E. Beatty, H.K. Hunter, and M.K. Baylies. 1995. Drosophila MEF2 is regulated by twist and is expressed in both the primordia and differentiated cells of the embryonic somatic, visceral and heart musculature. Mech. Dev. 50: 29 41.

Taylor, S.S., D.R. Knighton, J. Zheng, L.F.T. Eyck, and J.M. Sowadski. 1992. Structural framework for the protein kinase family. Annu. Rev. Cell Biol. 8: 429-462.

Thisse, C., F. Perrin-Schmitt, C. Stoetzel, and B. Thisse. 1991. Sequence specific transactivation of the Drosophila twist gene by the dorsal gene product. Cell 65: 1191-1201.

van der Geer, P. and T. Hunter. 1994. Receptor-protein tyrosine kinases and their signal transduction pathways. Annu. Rev.
Cell Biol. 10: 251-337.

Volk, T. and K. VijayRaghavan. 1994. A central role for epidermal segment border cells in the induction of muscle patterning in the Drosophila embryo. Development 120: 59-70.

Wharton, K.A., R.P. Ray, and W.M. Gelbart. 1993. An activity gradient of decapentaplegic is necessary for the specification of dorsal pattern elements in the Drosophila embryo. Development 117: 807-822.

$\mathrm{Wu}, \mathrm{X} ., \mathrm{K}$. Golden, and R. Bodmer. 1995. Heart development in Drosophila requires the segment polarity gene wingless. Dev. Biol. 169: 619-628.

Yamaguchi, T.P., K. Harpal, M. Henkemeyer, and J. Rossant. 1994. fgfr-1 is required for embryonic growth and mesodermal patterning during mouse gastrulation. Genes \& Dev. 8: 3032-3044 


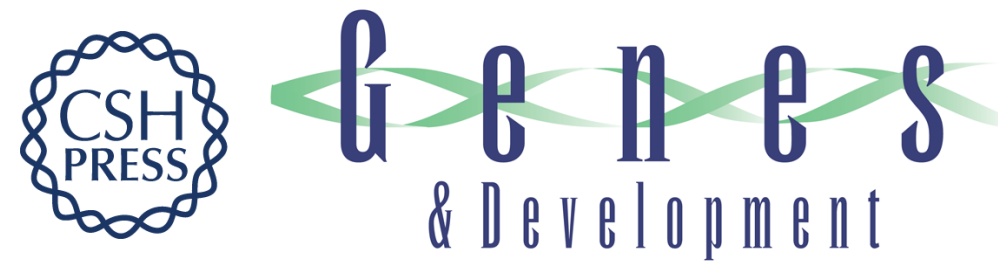

\section{heartless encodes a fibroblast growth factor receptor (DFR1/DFGF-R2) involved in the directional migration of early mesodermal cells in the Drosophila embryo.}

S Gisselbrecht, J B Skeath, C Q Doe, et al.

Genes Dev. 1996, 10:

Access the most recent version at doi:10.1101/gad.10.23.3003

References This article cites 72 articles, 37 of which can be accessed free at:

http://genesdev.cshlp.org/content/10/23/3003.full.html\#ref-list-1

License

Email Alerting Service

Receive free email alerts when new articles cite this article - sign up in the box at the top right corner of the article or click here.

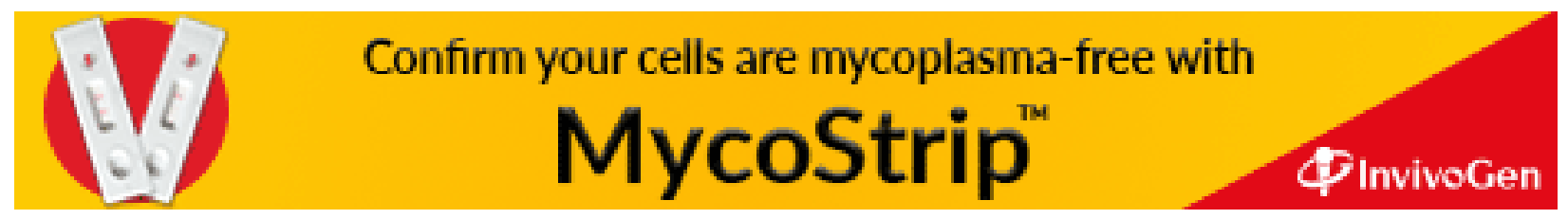

